\title{
Modelling nitrous oxide emissions from mown-grass and grain-cropping systems: Testing and sensitivity analysis of DailyDayCent using high frequency measurements
}

\footnotetext{
Nimai Senapati ${ }^{\text {a,b, }}{ }^{*}$, Abad Chabbi ${ }^{\text {a,b }}{ }^{*}$, André Faé Giostri ${ }^{c}$, Jagadeesh B. Yeluripati ${ }^{\mathrm{d}}$, Pete Smith ${ }^{\mathrm{e}}$

${ }^{a}$ French National Institute for Agricultural Research (INRA), Poitou-Charentes, URP3F, 86600 Lusignan, France

${ }^{b}$ French National Institute for Agricultural Research (INRA), Versailles-Grignon, UMR-ECOSYS, 78850 Thiverval-Grignon, France

${ }^{c}$ Federal University of Parana, Rua XV de Novembro, 1299 - Centro, Curitiba - PR, 80060-000, Brazil

${ }^{d}$ The James Hutton Institute, Craigiebuckler, Aberdeen AB15 8QH, Scotland, UK

${ }^{e}$ Institute of Biological and Environmental Sciences, University of Aberdeen, 23 St Machar Drive, Aberdeen AB24 3UU, UK

Corresponding author Email: nimai_senapati@yahoo.com; nimaisenapati@gmail.com; abad.chabbi@lusignan.inra.fr
}

\section{Abstract}

The DailyDayCent biogeochemical model was used to simulate nitrous oxide $\left(\mathrm{N}_{2} \mathrm{O}\right)$ emissions from two contrasting agro-ecosystems viz. a mown-grassland and a grain-cropping system in France. Model performance was tested using high frequency measurements over three years; additionally a local sensitivity analysis was performed. Annual $\mathrm{N}_{2} \mathrm{O}$ emissions of 1.97 and $1.24 \mathrm{~kg} \mathrm{~N} \mathrm{ha}^{-1} \mathrm{yr}^{-1}$ were simulated from mown-grassland and grain-cropland, respectively. Measured and simulated water filled pore space $(r=0.86, M E=-2.5 \%)$ and soil temperature $\left(r=0.96, M E=-0.63^{\circ} \mathrm{C}\right)$ at $10 \mathrm{~cm}$ soil depth matched well in mown-grassland. The model predicted cumulative hay and crop production effectively. The model simulated soil mineral $\mathrm{N}$ concentrations, particularly $\mathrm{NH}_{4}{ }^{+}$, reasonably, but the model significantly underestimated soil $\mathrm{NO}_{3}{ }^{-}$concentration under both systems. In general, the model effectively simulated the dynamics and the magnitude of daily $\mathrm{N}_{2} \mathrm{O}$ flux over the whole experimental period in grain-cropland $\left(r=0.16, M E=-0.81 \mathrm{~g} \mathrm{~N} \mathrm{ha}^{-1}\right.$ day $\left.^{-1}\right)$, with reasonable agreement between measured and modelled $\mathrm{N}_{2} \mathrm{O}$ fluxes for the mown-grassland $(r=0.63, M E=-$ $0.65 \mathrm{~g} \mathrm{~N} \mathrm{ha}^{-1} \mathrm{day}^{-1}$ ). Our results indicate that DailyDayCent has potential for use as a tool for predicting overall $\mathrm{N}_{2} \mathrm{O}$ emissions in the study region. However, in-depth analysis shows some systematic discrepancies between measured and simulated $\mathrm{N}_{2} \mathrm{O}$ fluxes on a daily basis. The current exercise suggests that the DailyDayCent may need improvement, particularly the sub-module 
responsible for $\mathrm{N}$ transformations, for better simulating soil mineral $\mathrm{N}$, especially soil $\mathrm{NO}_{3}{ }^{-}$ concentration, and $\mathrm{N}_{2} \mathrm{O}$ flux on a daily basis. The sensitivity analysis shows that many factors such as climate change, $\mathrm{N}$-fertilizer use, input error and parameter value could influence the simulation of $\mathrm{N}_{2} \mathrm{O}$ emissions. Sensitivity estimation also helped to identify critical parameters, which need careful estimation or site-specific calibration for successful modelling of $\mathrm{N}_{2} \mathrm{O}$ emissions in the study region.

\section{Introduction}

Nitrous oxide $\left(\mathrm{N}_{2} \mathrm{O}\right)$ is a potent greenhouse gas $(\mathrm{GHG})$, with a 100-year global warming potential, nearly 300 times that of carbon dioxide $\left(\mathrm{CO}_{2}\right)$ on a mass basis, contributing $6.24 \%$ (third most important contributor after $\mathrm{CO}_{2}$ and methane) to overall global radiative forcing (Forster et al., 2007; WMO, 2010). $\mathrm{N}_{2} \mathrm{O}$ has a critical role in the global energy balance, earth surface temperature and global climate change (IPCC, 2006). $\mathrm{N}_{2} \mathrm{O}$ is also the single-most important contributor to stratospheric ozone depletion, and a doubling of the atmospheric $\mathrm{N}_{2} \mathrm{O}$ concentration could decrease the ozone layer by $10 \%$, which ultimately would increase harmful ultra-violet radiation reaching the earth by 20\% (Crutzen and Ehhalt, 1977; Ravishankara et al., 2009). The atmospheric $\mathrm{N}_{2} \mathrm{O}$ concentration has increased nearly $21 \%$ from a pre-industrial level of about $270 \mathrm{ppbv}$ to $325.9 \mathrm{ppbv}$ in 2013, with an average increase rate of about $0.82 \mathrm{ppbv} \mathrm{yr}^{-1}$ for the last decade (WMO, 2014).

With a relatively long atmospheric life-time of about 114 years, the increasing atmospheric $\mathrm{N}_{2} \mathrm{O}$ concentration is a global concern (IPCC, 2007). Of the approximately $19 \mathrm{Tg} \mathrm{N}_{2} \mathrm{O}-\mathrm{N} \mathrm{yr}{ }^{-1}$ emitted globally, 40-50\% of total emissions derive from anthropogenic activities, (Forster et al., 2007; EPA, 2010; Syakila and Kroeze, 2011). Agriculture is the single biggest source of anthropogenic $\mathrm{N}_{2} \mathrm{O}$, contributing approximately $60-80 \%$ of global anthropogenic $\mathrm{N}_{2} \mathrm{O}$ emissions (Denman et al., 2007; Syakila and Kroeze, 2011). Expansion of agricultural land area, widespread use of nitrogenous (N) fertilizers, and increased manure application are the main drivers of enhanced $\mathrm{N}_{2} \mathrm{O}$ emissions from agricultural systems (IPCC, 2007; Davidson, 2009). With an increasing human population, and the 
consequent demand for higher food production, $\mathrm{N}_{2} \mathrm{O}$ emissions are likely to continue to rise in the coming decades (Mosier and Kroeze, 2000; Davidson, 2009; EPA, 2012). Important current challenges are the development of robust $\mathrm{N}_{2} \mathrm{O}$ inventories at national, regional and global scales, understanding of climate change impact of $\mathrm{N}_{2} \mathrm{O}$ emissions, and the definition of cost-effective potential mitigation options across different agro-ecosystems.

The predominant microbial processes of $\mathrm{N}_{2} \mathrm{O}$ emissions from agricultural soils are nitrification and denitrification, which are regulated by different climatic drivers (temperature, precipitation) (Liu et al., 2006, 2011), and soil physical (texture, structure, density, aeration, soil water properties, water filled porosity) and chemical ( $\mathrm{pH}$, soil $\mathrm{C}$ and $\mathrm{N}$ availability) properties (Čuhel et al., 2010; Signor and Cerri, 2013). Human induced activities, which affect soil temperature, moisture and aeration regimes, along with the availability of soil $\mathrm{C}$ and mineral $\mathrm{N}$, also influence $\mathrm{N}_{2} \mathrm{O}$ emissions under different agro-ecosystems. Significant emissions have been observed after tillage (Omonode et al., 2011), N-fertilizer and manure application (Das and Adhya, 2014), irrigation (Trost et al., 2013), and incorporation of crop residues (Shan and Yan, 2013). Across different cropping systems, choice of crops, types of crop rotations and crop growth stages also have an impact on $\mathrm{N}_{2} \mathrm{O}$ emissions (Jeuffroy et al., 2013). Intensive grassland management practices, such as mowing (cutting and subsequent harvesting) with frequent fertilization, have been reported to enhance $\mathrm{N}_{2} \mathrm{O}$ emissions (Rafique et al., 2011). However, underlying processes of $\mathrm{N}_{2} \mathrm{O}$ production, consumption and exchange between soil-atmosphere interface, and their interactions with biotic (e.g., plant species, microbial composition and diversity) and abiotic (e.g. climate, soil and management practices) factors are yet to be fully understood (Butterbach-Bahl et al., 2013). Again, variabilities in different controlling factors, both in space and time, result into enormous spatial and temporal variations in $\mathrm{N}_{2} \mathrm{O}$ emissions, adding uncertainty to efforts to upscale field measurements to national/regional/global $\mathrm{N}_{2} \mathrm{O}$ inventories (Mathieu et al., 2006; Groffman et al., 2009; Butterbach- 
Bahl et al., 2013). Future global warming or climate change feedbacks on $\mathrm{N}_{2} \mathrm{O}$ emissions are also uncertain (Butterbach-Bahl et al., 2013).

Process-based dynamic models, such as DailyDayCent (Parton et. al., 1998; Del Grosso et al., 2001, 2011) can be used not only to reduce the uncertainty/error originating from contrasting agro-ecosystems or spatio-temporal variability, but also help in testing scientific hypotheses, projecting $\mathrm{N}_{2} \mathrm{O}$ emissions under future land uses and climate change scenarios, and investigating potential mitigation strategies (Abdalla et al., 2010; Del Grosso et al., 2010; Kim et al., 2014). In recent decades, many process-based models have been developed to simulate $\mathrm{N}_{2} \mathrm{O}$ emission, describing different biotic and abiotic processes, along with different factors that control emissions, at differing levels of complexity. Although there is a need for simplicity in models, different ecosystem processes need to be simulated in sufficient detail. The model DailyDayCent was selected for simulation of daily $\mathrm{N}_{2} \mathrm{O}$ emission in our present study as because a) DailyDayCent is a generic model, thus can be used in different ecosystems including grassland and cropping systems, b) the model is of intermediate complexity, but important processes are represented mechanistically and are sufficiently detailed, c) required input data are often readily available, and d) the model performed at least reasonably across different regions (Stehfest and Müller, 2004; Jarecki et al., 2008; Del Grosso et al., 2008a, 2011; Abdalla et al., 2010; Scheer et al., 2014). The model is currently used to estimate $\mathrm{N}_{2} \mathrm{O}$ emissions for the U.S. National GHG Inventory conducted annually and reported to the United Nations Framework Convention on Climate Change (UNFCCC) (EPA, 2013). DailyDayCent is also being increasingly used for projection of $\mathrm{N}_{2} \mathrm{O}$ emission under various climate and land use change scenarios, and investigation potential mitigation options globally (Del Grosso et al., 2009; Abdalla et al., 2010). However, there is still considerable uncertainty in model simulation and further model improvement is needed for higher precision and accuracy (Del Grosso et al., 2010). Although the model has been tested under a range of agricultural systems around the 
world (Stehfest and Müller, 2004; Jarecki et al., 2008; Abdalla et al., 2010; Scheer et al., 2014),

2 before using the model in new environments, the model needs to be tested carefully. Further, more

3 model testing and improvement will ultimately help to improve our current understanding of

4 underlying process of $\mathrm{N}_{2} \mathrm{O}$ emissions and reduce uncertainty. Rigorous, in-depth model testing with

5 high frequency data of different streams, linked with different process information on nitrification

6 and denitrification, is important to make sure that the model simulates the dynamics of other

7 variables correctly along with $\mathrm{N}_{2} \mathrm{O}$ emissions, otherwise there could be apparent good model

8 performance for the wrong reasons and vice-versa (Del Grosso et al., 2011). However, these types of

9 studies are limited, particularly for the DailyDayCent model (Del Grosso et al., 2008a; Jarecki et al.,

10 2008; Scheer et al., 2014).

Analysis of model sensitivity to different parameters is an important task to assess how the

12 model will behave in a different environment other than the one in which it was developed (Smith

13 and Smith, 2007). Sensitivity analysis identifies critical inputs or model internal parameters, which

14 are the most influential on the model outputs, and also determines correlations between model

15 results and a given parameter (Smith et al., 2012). It is also important to identify sensitive

16 parameters so that uncertainty bounds for model simulations can be reduced with careful

17 consideration of those critical parameters. A local or a global sensitivity analysis has its own

18 advantages and disadvantages. Although few global sensitivity analysis of the

19 DayCent/DailyDayCent model for $\mathrm{N}_{2} \mathrm{O}$ emissions have been performed recently, either using an

20 inverse modelling approach for mostly internal model parameters (Rafique et al., 2014; Necpálová et

21 al., 2015), or applying a Monte Carlo-based simulation for model input parameters (Fitton et al.,

22 2014a, b), a systematic local sensitivity analysis changing one parameter at a time is rare,

23 particularly for model inputs and internal model parameters in contrasting agro-ecosystems. A local 
sensitivity analysis was performed to assess parameter sensitivity to model simulations in our present study. The main objectives of the present study were -

a) to test the ability of the model for simulation of $\mathrm{N}_{2} \mathrm{O}$ emissions under mown-grass and grain-cropping systems, using high frequency measurements, along with model testing for soil temperatures, soil water contents (water filled pore space), soil mineral nitrogen, soil organic carbon (SOC) and plant production,

b) to analyse sensitivity of the model towards different inputs and model parameters, along with their influence on model performance.

\section{Material and Methods}

\subsection{Experimental site and treatments}

The experimental site is located in Lusignan $\left(46^{\circ} 25^{\prime} 12,91^{\prime \prime} \mathrm{N} ; 0^{\circ} 07^{\prime} 29,35^{\prime \prime} \mathrm{E}\right)$ at the national long-term experimental observatory, Poitou-Charentes, France. The experimental site is about 22 ha, and is part of a long-term observatory for environmental research (Agroecosystems, Biogeochemical Cycles and Biodiversity, SOERE-ACBB; http:/www.soere-acbb.com) (Fig. 1). Average air temperature and annual precipitation during the experimental period March 2011 to February 2014 were $12.3^{\circ} \mathrm{C}$ and $950 \mathrm{~mm}$, respectively (Fig. 2). Summer was hot and dry, whereas winter was cold and moist. August was the hottest month (average maximum temperature $\sim 25.7^{\circ} \mathrm{C}$ ) and the coldest month was February (average minimum temperature $\sim 0.6^{\circ} \mathrm{C}$ ). December received the highest precipitation (159 mm month $\left.{ }^{-1}\right)$, whereas March and August received the lowest precipitation (33-40 mm month ${ }^{-1}$ ). The most favourable climatic conditions for plant growth, in terms of average air temperature and precipitation, were found in spring followed by autumn, summer and winter. The experimental site was designed conjointly by INRA and CNRS research organisation institutes to increase understanding of the effects of temporary grassland management and mixed arable 
cropping/grassland systems on environmental outputs. The original experiment was established in spring (March-April), 2005. Before 2005, part of the observatory was under either managed grassland, grain-cropping or ley-arable rotations for at least 17 years. The soil profile can be divided into two main domains: upper soil horizons are characterized by a loamy texture, classified as Cambisol, whereas lower soil horizons are clayey rubefied horizons, rich in kaolinite and iron oxides, classified as a Paleo-Ferralsol. A detailed description of the study site can be found elsewhere (Chabbi et al., 2009; Moni et al., 2010; Senapati et al., 2014). Two paddocks (P1/T3 and P2/T5), each about 3 ha in size and almost rectangular in shape, were selected from the original experiment for the present study (Fig. 1). Temporary $C_{3}$-grass was sown in both the paddocks during spring in 2005. The herbaceous layer in the grassland consisted of a mixture of three grass species viz. Lolium perenne L., Festuca arundinacea Schreb. and Dactylis glomerata L. Each of these two paddocks was subject to equal treatment viz. regular mowing (cutting) and hay harvesting with application of nitrogen $(\mathrm{N})$ fertilizer without returning any off-site animal excreta for the time period 2006-2010. As a part of the original experiment of the ley-arable system (6-yrs. Grassland - 3-yrs. cropping), one mown-grass paddock (P1/T3) was converted to grain cropping in March, 2011, with a summer-corn (Zea mays L.) - winter-wheat (Triticum sp) - winter-barley (Hordeum vulgare L.) rotation till February, 2014, hereafter referred to as the "grain-cropland". The sown corn, wheat and barley varieties were PR38V12 PIONER, Caphorn and Limpid, respectively. The second mowngrass paddock (P2/T5) was continued with the same grass mowing treatment from March 2011 to February 2014, hereafter referred to as the "mown-grassland". Fertilizer N application rate and the timing of crop sequences were adjusted every year using the PC-AZOTE software program for near maximum plant production (Angevin, 1999; Kunrath et al., 2015). Nitrogen Nutrition Index (NNI) was estimated regularly according to the method described by Farruggia et al. (2004) and Duru (2004). The timing and rate of fertilizer applications were regulated to maintain an NNI of between 
0.9 and 1.0, i.e. close to a non-limiting $\mathrm{N}$ nutrition allowing for potential herbage production

2 (Lemaire et al., 2008). $\mathrm{N}_{2} \mathrm{O}$ emission was measured in the mown-grassland and grain-cropland

3 continuously for three years from March 2011 to February 2014, completing a full cycle of grain-

4 cropping and grass-mowing. The details of the management practices of the two treatments during

$5 \quad$ 2011-2014 are summarized in Table 1.

6

7

8 data base Climatik, maintained by INRA AgroClim. Daily maximum and minimum air temperature

9 and precipitation for the period 2005-2014 were used as climatic driving variables for the

\subsection{Meteorological measurements}

Daily weather parameters were measured on the site of the experiment and available on the DailyDayCent model. For the model spin-up run, similar past weather data of 30 years (1975-2004) were used.

\subsection{Soil moisture and temperature measurements}

Volumetric soil water content was measured in the mowing paddock with TDR probes continuously from 2011-2013 at half-hourly intervals at 6 soil depths (10, 20, 30, 60, 80 and 100 $\mathrm{cm})$, whereas soil temperature was measured with temperature probes at 7 soil depths $(5,10,20,30$, 60, 80 and $100 \mathrm{~cm}$ ). Water filled pore space (WFPS) was estimated from soil moisture measurements by using the equation:

WFPS $(\%)=\left[\theta_{v} /(1-\right.$ bulk density/particle density $\left.)\right] \times 100 \quad($ Linn and Doran, 1984)

where $\theta_{v}$ is the percent volumetric water content. We used both WFPS and soil temperature data on daily time scale at the $10 \mathrm{~cm}$ depth for model testing in mown-grassland. However, soil water and temperature were not measured in the cropping paddock due to resource constraints.

\subsection{Soil organic carbon and mineral nitrogen measurements}


Total SOC stocks in the top $30 \mathrm{~cm}$ soil layer were measured in both mown-grassland and

2 cropland in the year 2005, 2008, 2011 and 2014. Although our present study of the $\mathrm{N}_{2} \mathrm{O}$ emissions

3 was for the period 2011-2014, we used all the available SOC measurements from 2005-2014 for

4 model evaluation. To match with the model output for SOC, since DailyDayCent simulates SOC

5 only for the top $20 \mathrm{~cm}$ soil layer, measured SOC stocks in the $0-30 \mathrm{~cm}$ soil layer were converted into

6 SOC stocks of the $0-20 \mathrm{~cm}$ soil layer by assuming a minimum and maximum distribution of 60 and

$790 \%$ of total SOC in the top $20 \mathrm{~cm}$ soil layer. However, for simplification, we used SOC stock for

8 the top $20 \mathrm{~cm}$ soil layer as an average of $75 \%$ of the top $30 \mathrm{~cm}$ soil layer. Soil mineral nitrogen

9 concentrations $\left(\mathrm{NO}_{3}{ }^{-}\right.$and $\left.\mathrm{NH}_{4}{ }^{+}\right)$were measured from fresh soil samples during 2011-2013. Briefly,

$1025 \mathrm{~g}$ soil sample was extracted with $1 \mathrm{M} \mathrm{KCl}$ (1:3 soil: solution ratio). The extract was centrifuged

11 for $15 \mathrm{~min}$ at $5800 \mathrm{~g}$ and filtered through a No.3 Durieux paper disc. The mineral nitrogen

12 concentrations in the soil extract were analysed by continuous flow colorimetry (TRAACS 2000,

13 Irama corp, Milwaukee,WI, USA). The $\mathrm{NO}_{3}{ }^{-}$concentration was determined as described by

14 Kamphake et al. (1967).

\subsection{Plant production}

Harvested hay production from the mown-grassland was measured as megagram of dry matter (DM) per hectare $\left(\mathrm{Mg} \mathrm{DM} \mathrm{ha}^{-1}\right)$ after each mowing event. There were 3-4 mowing events annually on irregular dates (Table 1). Cumulative harvested hay production was used for testing model performance over the three year cycle. Similarly, total above ground biomass, grain and straw yield were estimated in the units of $\mathrm{Mg} \mathrm{DM} \mathrm{ha}^{-1}$ after harvesting events on cropland.

\subsection{Flux measurement}

$\mathrm{N}_{2} \mathrm{O}$ and $\mathrm{CO}_{2}$ flux were measured simultaneously using six automatic chambers from 20112014 in both mown-grassland and grain-cropland. We used the same automatic chamber and method 
for flux measurements in our experiment as described in detail by Laville et al. (2011). Briefly, the

2 automatic chambers, with dimensions of $0.7 \mathrm{~m} \times 0.7 \mathrm{~m} \times 0.30 \mathrm{~m}$, were made of stainless steel to

3 prevent air constituents such as ozone and nitrogen dioxide reacting with the chamber walls. Each

4 chamber frame was pressed into the earth to a depth of $9 \mathrm{~cm}$, giving an effective height above

5 ground of around $20 \mathrm{~cm}$ and headspace of $98 \mathrm{~L}$. A cover mounted on pivot arms was moved by an

6 electric actuator to open and close the chamber. A small vent of 4-mm in diameter provided the

7 pressure equilibrium between the inside and outside of the chamber. The $\mathrm{N}_{2} \mathrm{O}$ and $\mathrm{CO}_{2}$ gas analysers

8 were connected serially and their outlet flow was fed back into the chamber. The $\mathrm{N}_{2} \mathrm{O}$ and $\mathrm{CO}_{2}$

9 concentrations were measured by infrared absorption spectrometry (Thermo-Environmental

10 Instruments Inc., model 46C, Franklin, Massachusetts; and LI-COR Inc., model Li-840, Lincoln,

11 Nebraska, respectively). The sensitivity thresholds (noise level) of the analysers were around $10 \mathrm{ppb}$

12 for $\mathrm{N}_{2} \mathrm{O}$ and $1.5 \mathrm{ppm}$ for $\mathrm{CO}_{2}$. The gas analysers were calibrated once a month, using certified gas

13 tanks. Each chamber was sampled in 10 seconds intervals, for 15 minutes, through the analysers, and

14 the outflow of the $\mathrm{N}_{2} \mathrm{O}$ and $\mathrm{CO}_{2}$ analysers was fed back to the chamber. Raw concentrations were

15 recorded every 10 seconds using a data logger (CR1000, Campbell Scientific, Inc, US). Each

16 chamber was closed for 15-min periods, and with 6 chambers the complete measurement cycle thus

17 lasted for 90 minutes. The six chambers device therefore allowed 96 flux measurements per day or

1816 mean fluxes per day for each of the 6 chambers. $\mathrm{N}_{2} \mathrm{O}$ and $\mathrm{CO}_{2}$ fluxes were calculated from the

19 variations over time in the slopes of the gas outlet concentration $\left(\mathrm{C}_{\text {out }}\right)$, using the following equation:

$F=(V / A) \times\left(d C_{\text {out }} / d t\right)$

21 where $F$ is the flux (in $\mathrm{ppb} \mathrm{s}^{-1}$ ), $\mathrm{V}$ is the chamber headspace volume $\left(\mathrm{m}^{3}\right), A$ is the ground area

22 covered by the chamber $\left(\mathrm{m}^{2}\right)$ and $d C_{\text {out }} / d t$ is the time derivative of the outlet concentration (ppb

$23 \mathrm{~s}^{-1}$ ). Fluxes were converted from $\mathrm{ppb} \mathrm{s}^{-1}$ to $\mathrm{ng} \mathrm{N} \mathrm{m}^{-2}$ using the following equation: 
$\mathrm{ng} \mathrm{N} \mathrm{m}{ }^{-2}=(M \times P / R T) \times \mathrm{ppb}$

2

3

4

5 discarded.

\subsection{DailyDayCent model description:}

where, $M$ is the gas molar mass in gram per mol, $P$ is the air pressure fixed at $1013 \times 10^{2} \mathrm{~Pa}, R$ is the perfect gas constant $\left(8.31 \mathrm{~J} \mathrm{~K}^{-1} \mathrm{~mol}^{-1}\right)$ and $T$ is the absolute $(K)$ air temperature in the chamber headspace, measured during the gas accumulation. There were few gaps in $\mathrm{N}_{2} \mathrm{O}$ flux measurements due to management practice, poor quality data and instrumental failure. During the ploughing events, the chambers were generally removed for three days. $\mathrm{N}_{2} \mathrm{O}$ flux measurements were checked taking $\mathrm{CO}_{2}$ flux as reference, and with abnormal measured $\mathrm{CO}_{2}$ flux, $\mathrm{N}_{2} \mathrm{O}$ flux measurements were

The model DailyDayCent is the daily time-step version of the CENTURY biogeochemical model, simulates daily exchanges of carbon, nutrients and trace gases among the atmosphere, vegetation and soil (Parton et al., 1998; Del Grosso et al., 2001, 2011). Key sub-models include plant production, decomposition of dead plant material and soil organic matter, soil water and temperature dynamics, and $\mathrm{N}$ gas fluxes. Flows of $\mathrm{C}$ and $\mathrm{N}$ between the different soil organic matter pools are controlled by the size of the pools, $\mathrm{C} / \mathrm{N}$ ratio and lignin content of material, and abiotic water/temperature factors. The land surface sub-model simulates soil water and temperature for each horizon throughout the defined depth of the soil profile. The soil water sub-model particularly simulates soil water content and water fluxes (e.g., run off, leaching, evaporation and transpiration). Saturated water flow occurs on days that receive rainfall, irrigation, or snow melt, and unsaturated flow occurs on all days that do not have water inputs sufficient to saturate the profile and can be up or down the profile depending on matric and gravitational potentials. The plant growth sub-model simulates plant productivity as a function of genetic potential, phenology, temperature, soil water, nutrient availability, shading and solar radiation (i.e. energy biomass conversion factor). Net primary productivity is divided among leafy, woody, and root compartments on the basis of plant type and 
phenology. The root/shoot ratio of NPP allocation is a function of soil water content and nutrient

2 availability. Plant germination date could either be specified or calculated as a function of soil temperature; similarly harvesting date could either be specified or calculated as a function of accumulated growing degree days since germination. Management and disturbance events (e.g. 5 cultivation, fertilization, grazing, cutting, fire, irrigation etc.) can easily be implemented. The death rate of plant compartments is controlled by soil water, temperature, season, and plant-specific senescence parameters. Dead plant material is divided into structural (high $\mathrm{C} / \mathrm{N}$ ) and metabolic (low $\mathrm{C} / \mathrm{N})$ components. In the SOM submodule, soil organic matter (SOM) is divided into three pools (active, slow, and passive) based on their turnover rates. SOM is simulated in the top $20 \mathrm{~cm}$ soil layer as a sum of dead plant matter and three SOM pools on the basis of their decomposition rates. Decomposition of litter and soil organic matter mineralization are functions of substrate availability, substrate quality (lignin content, $\mathrm{C} / \mathrm{N}$ ratio), and water and temperature stress, soil texture and tillage intensity. Soil nitrate $\left(\mathrm{NO}_{3}{ }^{-}\right)$is distributed throughout the soil profile and available for leaching into water content and soil physical properties related to texture, which influences gas diffusivity. The 
by the input $\left(\mathrm{NO}_{3}{ }^{-}\right.$, respiration, WFPS $)$that is most limiting. $\mathrm{N}_{2} \mathrm{O}$ emissions are calculated from $\mathrm{N}_{2}+\mathrm{N}_{2} \mathrm{O}$ gas emissions and a $\mathrm{N}_{2} / \mathrm{N}_{2} \mathrm{O}$ ratio adjustment coefficient (n2n2oadj). The current DailyDayCent model allows the user to vary $n 2 n 2 o a d j$ along with other soil $\mathrm{N}$ dynamic parameters viz. maximum daily nitrification amount (MaxNitAmt), fraction of new net mineralization that goes to $\mathrm{NO}_{3}$ (netmn_to_no3), maximum proportion of nitrified $\mathrm{N}$ that is lost as $\mathrm{N}_{2} \mathrm{O}$ at field capacity ( $N_{2}$ Oadjust_fc), and minimum proportion of nitrified $\mathrm{N}$ that is lost as $\mathrm{N}_{2} \mathrm{O}$ at wilting point $\left(N_{2}\right.$ Oadjust_wp). These above five important soil $\mathrm{N}$ parameters can be found in "sitepar.in" file. Daily maximum/minimum air temperature and precipitation, soil texture by horizon, land cover/use data, and timing and information of field and crop management events are needed as primary model inputs. Model simulated outputs include daily $\mathrm{N}$-gas flux $\left(\mathrm{N}_{2} \mathrm{O}, \mathrm{NO}_{\mathrm{x}}, \mathrm{N}_{2}\right), \mathrm{CO}_{2}$ flux from heterotrophic soil respiration, soil organic $\mathrm{C}$ and $\mathrm{N}, \mathrm{NPP}$, soil $\mathrm{NH}_{4}{ }^{+}$in top $15 \mathrm{~cm}$ soil, $\mathrm{NO}_{3}{ }^{-}$, water content, WFPS and temperature by soil horizon, $\mathrm{H}_{2} \mathrm{O}$ and $\mathrm{NO}_{3}{ }^{-}$leaching, and other ecosystem parameters. A more detailed description of the model can be found elsewhere (Parton et al., 1998, 2001; Del Grosso et al., 2001, 2008b, 2011, Necpálová et el., 2015).

\subsection{Model set-up, parameterization, calibration and simulation: DailyDayCent was set-up using} site specific parameters viz. texture, bulk density (BD), field capacity (FC), wilting point (WP), hydraulic conductivity, SOC, pH etc., measured or estimated in 2005 (Table 2). Soil water characteristics (FC, WP and saturated hydraulic conductivity) were estimated from texture and organic matter using the algorithm developed by Saxton and Rawls (2006). But, soil water content (SWC) was found from preliminary model run to be overestimated in our site. All three estimated soil water characteristics were tested for possible model overestimation of SWC, and a reasonable model simulation of SWC was obtained when FC was reduced by $10 \%$. To reduce any uncertainty originating from the estimation of soil water characteristics, in simulation of SWC, WFPS and subsequently $\mathrm{N}_{2} \mathrm{O}$ emissions, estimated $\mathrm{FC}$ was calibrated by reducing the value by $10 \%$ in our 
model set-up, according to the recommendation of the DailyDaycent developer (Del Grosso et al., 2011).

As $\mathrm{N}_{2} \mathrm{O}$ emissions are sensitive to $\mathrm{SOC}$ and prior land-use, and all the SOC pools including different nutrients are rarely known at the beginning of a current experiment of interest, simulation of native vegetation followed by historical land uses are generally recommended for the DailyDayCent model to establish a modern-day base line (Del Grosso et al., 2006, 2011). To establish a modern-day base line at the starting of our main experiment in 2005 , model simulations were performed in three time blocks according to historical records and published literature viz. (1) native temperate-deciduous forest ( $\mathrm{AD} 1$ to plough out-1750), (2) historical land use - (a) grass grazing (1751-1845), (b) ley-arable rotation (1846-1980), and (3) modern day agriculture with known ley-arable rotation (1981-2004) (Mather et al., 1999; Chabbi et al., 2009; Kaplan et al., 2009; Senapati et al., 2014). Thirty years (1975-2004) of available daily weather data, as mentioned in the meteorological measurement section, was used to run the model from AD 1 to 2004. A spin-up simulation (native forest) of at least 1600 years was needed to achieve relatively stable SOC pools before implementing the base simulation (plough out and historical land use). The equilibrium simulation suggested that the SOC pool in the top $20 \mathrm{~cm}$ soil layer under the native temperatedeciduous forest ( $\left.81 \mathrm{Mg} \mathrm{C} \mathrm{ha}^{-1}\right)$ decreased by $42 \%$ within 100 years of agricultural use ( 47 Mg C ha $^{-1}$ ) by 1850 (Fig. 3). From 1850 onwards, SOC further decreased to $37-39 \mathrm{Mg} \mathrm{C}^{-1}$ in 2005 , representing another $17-21 \%$ loss within 155 years compared to the level in 1850 . The equilibrium simulation was consistent with the literature, indicating a mean SOC stock in the top $30 \mathrm{~cm}$ soil layer under various native forest of 60-94 $\mathrm{Mg} \mathrm{C} \mathrm{ha}^{-1}$ in France (Arrouays et al., 2001; Martin et al., 2011; Meersmans et al., 2012), and a loss in SOC ranging from 30-70\% due to land use change from native forest to agriculture in France (Arrouays and Pelissier, 1994; Balesdent et al., 1998). Other studies around the world also reported a 30-60\% loss in SOC after clearing of native forest followed by 
agricultural uses (Guo and Gifford, 2002; Poeplau et al., 2011). Simulated SOC stocks in 2005 were

2 similar to our field measurements in the same year in mown-grassland (38.9 $\left.\mathrm{Mg} \mathrm{C} \mathrm{ha}^{-1}\right)$ and grain3 cropland (36.6 $\left.\mathrm{Mg} \mathrm{C} \mathrm{ha}^{-1}\right)$ (Fig. 3).

In the plant growth sub-model, temperate mown-grass was simulated as a perennial plant

5 with dynamic $\mathrm{C}$ allocation, whereas the three grain crops (corn, wheat and barley) were simulated as grain filling annuals with growing degree day (GDD) and dynamic $\mathrm{C}$ allocation. The plant growth

7 sub-model parameters were adjusted based on literature values, previous model experience, preliminary model runs and field measurements (Del Grosso et al., 2011; Chang et al., 2013; Rafique

9 et al., 2014; Necpálová et al., 2015). The parameters related to plant growth and biomass 10 accumulation in the present study are listed in Table 3. The simulated harvested $\mathrm{C}$ in the mown11 grassland, and simulated grain and straw $\mathrm{C}$ in the cropland were manually converted to dry matter by 12 dividing the $\mathrm{C}$ with the measured $\mathrm{C}$ concentrations in hay (41\%), grain (45\%) and straw (41\%). 13 Table 3 also shows five default soil $\mathrm{N}$ dynamics parameters used in the "sitepar.in" file. No other 14 model parameter was modified or adjusted. After establishing the modern-day base line in 2005 for 15 model simulation in our experiment, as described above, the model run was continued in both mown-grassland and grain-cropland until 2014, using field management practices and climatic 17 variables as drivers.

\subsection{Statistical analysis}

The following tests were used to evaluate the performance of the DailyDayCent model: sample correlation coefficient (r), root mean square error (RMSE) and mean error $(M E)$, as defined in Smith et al. $(1996,1997)$ and summarized in Smith and Smith (2007). The significance of $r$ was

22 tested using a $F$-test $(P=0.05)$, whereas significance of $M E$ was evaluated using Student's t-test 23 (two-tailed, critical at 2.5\%). On the other hand, RMSE was tested by comparing to its value at $95 \%$ 24 confidence intervals $\left(R M S E_{95 \%}\right)$ (Table 4). The statistic $r$ tests the correlation between measured and 
simulated values, and thus describes to what extent the dynamics or variability can be captured by the model irrespective of any systematic errors. On the other hand RMSE and ME evaluate the coincidence, and thus quantify the difference between simulated and measured values. Replication values of some measured variables, such as WFPS and soil temperature, were not available in our experiment, but the same were available for other measurements $\left(\mathrm{N}_{2} \mathrm{O}\right.$ flux, soil mineral $\mathrm{N}$ concentration, SOC and plant yield). For this reason, two different coincidence analysing statistics (ME and RMSE) were used to exploit the advantage of replicated measurements whenever available in our experiment. For an ideal fit, $r$ equals 1 , and $M E$ and $R M S E$ equal zero.

\subsection{Sensitivity analysis}

( Model sensitivity to a total of 14 parameters (2-climatic input parameters, 7-soil parameters, fertilizer $\mathrm{N}$ quantity, and 5-soil $\mathrm{N}$-dynamics parameters in "sitepar.in" file) was conducted by altering one parameter at a time (local sensitivity analysis;Smith and Smith, 2007; Table 5). Sensitivities of simulated variables were examined by changing daily air temperature by $\pm 1^{\circ} \mathrm{C}$ and $\mathrm{pH}$ by \pm 1 unit, whereas sensitivity of model simulations to all other parameters were examined by changing $\pm 10 \%$ of the parameter base values. Sensitivity was expressed as percentage change in the simulated variable compared to its original base simulation over the experimental period 2011-2014. The sensitivities $>10 \%, 5-10 \%$ and $<5 \%$ were considered high, moderate and weak in our present study. Additionally, to test whether those changes $\left( \pm 1^{\circ} \mathrm{C}\right.$ in air temperature, \pm 1 unit in $\mathrm{pH}$ and $\pm 10 \%$ in others) in parameter/inputs had a significant influence on model performance, the influence of the individual parameter error or uncertainty on model performance was tested against measurements (Table 5). 3. Results

\subsection{Modelling soil water (water filled pore space) and temperature}

Over the experimental period, significant agreement was obtained $(r=0.86, M E=-2.5 \%)$ between modelled and measured WFPS at $10 \mathrm{~cm}$ soil depth in mown-grassland (Fig. 4 and Table 4). 
The model successfully simulated seasonal dynamics, and the processes of soil drying and wetting during summer and autumn, respectively (Fig. 4). However, some discrepancies were found between simulation and measurements during different seasons. For example, the model moderately overestimated WFPS (9-27\%) during summer-autumn; in contrast WFPS was slightly underestimated (8\%) during spring. Model performance for WFPS was not evaluated in graincropland due to the unavailability of measured data. However, averaged over mown-grassland and grain-cropland, simulated WFPS at $10 \mathrm{~cm}$ soil depth was high (60-61\%) during winter and low in summer (35-41\%) (Fig. 4). The simulated WFPS reached the highest point (92\%) in winter, and was lowest (11\%) during summer. Simulated WFPS under mown-grassland and grain-cropland was almost equal during winter and autumn, but some discrepancy was found from spring to summer. In 2011, WFPS was relatively higher under corn compared to mown-grass during spring; on the other hand, WFPS was lower under corn during late-summer to early autumn. Interestingly, WFPS was higher under wheat and barley during summer compared to mown-grass in 2012 and 2013, respectively. Averaged over the whole experimental period, simulated WFPS at $10 \mathrm{~cm}$ soil depth was $49 \%$ in mown-grassland, whereas WFPS was $4.5 \%$ greater in cropland compared to grassland (Fig. 4).

The simulated soil temperature at $10 \mathrm{~cm}$ soil depth was highly correlated $(r=0.96)$ with measurements over the study period in mown-grassland, with non-significant simulation error $(M E=$ $-0.63^{\circ} \mathrm{C}$ ) (Fig. 5 and Table 4). DailyDaycent also accurately captured the seasonal pattern of soil temperature, both in terms of time and magnitude. However, the model moderately overestimated soil temperature by $21 \%$ during late-summer to winter. Model performance for soil temperate was not evaluated in grain-cropland for to the unavailability of measured data. Averaged over of the two systems, mean simulated soil temperature across the experimental period at the $10 \mathrm{~cm}$ soil depth was $14.1^{\circ} \mathrm{C}$ (Fig. 5). Summer soil temperature peaked up to $25^{\circ} \mathrm{C}$, whereas minimum temperature 
lowered down to $0.78^{\circ} \mathrm{C}$ during winter. Simulated soil temperature was higher in cropland during

2 spring compared to mown-grassland in 2011, but it was lower during late summer-early autumn in

3 the same year. In contrast, an opposite trend in simulated soil temperature was found in 2012 and

4 2013. Averaged simulated soil temperature at the $10 \mathrm{~cm}$ soil depth was higher in grain-cropland, by

5 around $1^{\circ} \mathrm{C}$, compared to mown-grassland.

6

7

8

9 production efficiently ( $r=0.99, M E=-1.40 \mathrm{Mg} \mathrm{DM} \mathrm{ha}^{-1}$ ) in mown-grassland (Fig. 6-7 and Table 4).

10 Over all three grain-crops in cropland, simulated plant production was reasonable $(r=0.88, M E=$

11 1.22 $\mathrm{Mg} \mathrm{DM} \mathrm{ha}{ }^{-1}$ ). The model simulated total above-ground biomass, grain and straw yield

12 satisfactorily for wheat and barley, but the model underestimated corn production significantly (Fig.

137 and Table 4). On each mowing events in grassland, simulated above-ground live biomass

14 decreased sharply on mowing dates (Fig. 6). . The growth of winter wheat and barley in cropland

15 was slow at the beginning, due to lower winter temperature, and thereafter picked-up with increasing

16 air temperature (Fig. 6). Simulated cumulative plant N-uptake over the three year period was almost

17 similar in magnitude in both mown-grassland and grain-cropland (355-413 $\left.\mathrm{kg} \mathrm{N} \mathrm{ha}^{-1}\right)$. Simulated

18 cumulative total $\mathrm{N}$-leaching over the same period was found in the range $163-517 \mathrm{~kg} \mathrm{~N} \mathrm{ha}^{-1}$, and the

19 result indicates that total leaching loss of $\mathrm{N}$ from grassland was 2.2 times greater than cropland (Fig

$20 \quad 6)$.

21

3.3. Modelling soil organic carbon and soil mineral nitrogen 
2 layer was found in both systems (Fig. 2 and Table 4). The measured and modelled SOC were close,

3 but with a non-significant $(p<0.05)$ correlation between them. The results show that the model

4 efficiently simulated the magnitude of SOC, but was not so well able to simulate SOC dynamic.

5 However, both measured and simulated values demonstrated that SOC remained relatively constant

6 over the experimental period under both the agro-ecosystems.

Overall, reasonable model prediction of soil $\mathrm{NH}_{4}{ }^{+}$in top $15 \mathrm{~cm}$ soil layer $(r=0.23-0.29, M E$

$8=0.01-0.42 \mathrm{mg} \mathrm{N} \mathrm{kg}^{-1}$ soil) was achieved in both the ecosystems (Fig. 8 and Table 4). Significant

9 coincidence was found between measured and simulated $\mathrm{NH}_{4}{ }^{+}$in both systems, but no significant

10 correlation was obtained between them. The model significantly underestimated soil $\mathrm{NO}_{3}{ }^{-}$

11 concentration $\left(M E=5.5-16.4 \mathrm{mg} \mathrm{N} \mathrm{kg}^{-1}\right.$ soil $)$ in the top $30 \mathrm{~cm}$ soil layer under both systems, and no

12 significant correlation ( $r=-0.19$ to -0.22 ) was obtained between modelled and measured ${\mathrm{soil} \mathrm{NO}_{3}}^{-}$

13 (Fig. 8 and Table 4). ..,=. Simulated soil mineral $\mathrm{N}$ concentration was mainly driven by $\mathrm{N}-$

14 fertilization events. There were sharp peaks in simulated $\mathrm{NH}_{4}{ }^{+}$concentration after each of the

15 fertilization events, depending on the amount of applied fertilizer-N. Similarly, simulated $\mathrm{NO}_{3}{ }^{-}$

16 concentration followed the same trends as of $\mathrm{NH}_{4}{ }^{+}$, but the peaks of $\mathrm{NO}_{3}{ }^{-}$concentration were

17 relatively blunt compared to that of $\mathrm{NH}_{4}{ }^{+}$. Comparing the two systems, averaged simulated soil

18 mineral $\mathrm{N}$ concentration in mown grassland was 1.1-2.5 times greater compared to cropland.

19 Averaged measured soil $\mathrm{NH}_{4}{ }^{+}$concentration was 1.03 times greater in mown-grassland compared to

20 grain-cropland, but measured $\mathrm{NO}_{3}{ }^{-}$was 0.55 times greater in cropland compared to mown-grassland.

\section{3.4. Modelling nitrous oxide flux}

In mown-grassland, the model simulated the dynamics and the magnitude of $\mathrm{N}_{2} \mathrm{O}$ flux

23 reasonably well $\left(r=0.63, M E=-0.65 \mathrm{~g} \mathrm{~N} \mathrm{ha}^{-1}\right.$ day $\left.^{-1}\right)$ over the whole experimental period from 
March 2011 to February 2014 (Fig. 9 and Table 4). Significant correlation $(p<0.05)$ was obtained

2 between measured and modelled daily $\mathrm{N}_{2} \mathrm{O}$ fluxes, but among the two coincidence analysing

3 statistics viz. ME and RMSE, only RMSE was found to be significant at the $95 \%$ confidence limit,

4 indicating significant simulation error for $\mathrm{N}_{2} \mathrm{O}$ emission when only accounting for measurement

5 error. Model simulations of $\mathrm{N}_{2} \mathrm{O}$ flux in different seasons and years showed variability. In 2011, two

6 fertilization events were immediately followed by two simulated small $\mathrm{N}_{2} \mathrm{O}$ flux peaks in spring.

7 The model simulated the timing and the magnitude of measured $\mathrm{N}_{2} \mathrm{O}$ peaks correctly throughout the

8 year 2011. Three simulated $\mathrm{N}_{2} \mathrm{O}$ peaks were found after three fertilization events during spring-early

9 summer in 2012. But, no peak was observed in the measurements after the first and third fertilization

10 events in March and July, respectively. The model overestimated $\mathrm{N}_{2} \mathrm{O}$ emission during the main

11 grass growing period in spring, but correctly predicted an extended measured peak of 5-10 $\mathrm{g} \mathrm{N} \mathrm{ha}^{-1}$

12 day $^{-1}$ in autumn. The year 2013 was marked with four mowing and five fertilization events during

13 late-winter to early-autumn. The model reasonably simulated the dynamics and magnitude of $\mathrm{N}_{2} \mathrm{O}$

14 flux in 2013, but the model overestimated emissions in early spring. N-fertilizer was applied at the

15 highest rate of $90 \mathrm{~kg}-\mathrm{N}$ ha ${ }^{-1}$ in February, but only a small peak was found in both simulation and

16 measurement after the fertilization event. Two moderate $\mathrm{N}_{2} \mathrm{O}$ peaks were measured in May after the

17 second $\mathrm{N}$-fertilizer application of $60 \mathrm{~kg}-\mathrm{N} \mathrm{ha}{ }^{-1}$, and the both peaks were simulated satisfactorily. But

18 after the third fertilization event $\left(60 \mathrm{~kg}-\mathrm{N} \mathrm{ha}^{-1}\right)$ in June, the model failed to simulate the largest

19 measured peak of about $250 \mathrm{~g} \mathrm{~N} \mathrm{ha}^{-1} \mathrm{day}^{-1}$, and the measured peaks were 3-4 times greater and late

20 by around one week compared to the simulated peaks. There were two more moderate simulated

$21 \mathrm{~N}_{2} \mathrm{O}$ peaks (36-56 $\mathrm{g} \mathrm{N} \mathrm{ha}^{-1} \mathrm{day}^{-1}$ ), after the last two fertilization events in 2013; but the model

22 overestimated the $\mathrm{N}_{2} \mathrm{O}$ peak after the last fertilization event. Interestingly, some small negative $\mathrm{N}_{2} \mathrm{O}$

23 fluxes $\left(>-10 \mathrm{~g} \mathrm{~N} \mathrm{ha}^{-1} \mathrm{day}^{-1}\right)$ were found in measurements under mown-grassland during May-July in

242011 and August-October in 2012. However, no negative flux was simulated by DailyDayCent. 
In cropland, significant agreement between measured and simulated daily $\mathrm{N}_{2} \mathrm{O}$ fluxes was

2 obtained over the whole experimental period (Fig. 9 and Table 4). A significant correlation $(r=$

3 0.16) was obtained between measured and simulated fluxes at $P<0.05$, and there was no significant

4 simulation error at $P<0.025$ or $95 \%$ confidence limit. In general, almost every $\mathrm{N}$-fertilization event

5 was immediately followed by a simulated peak in $\mathrm{N}_{2} \mathrm{O}$ emissions, irrespective of season and year.

6 Both measurement and simulation showed a small $\mathrm{N}_{2} \mathrm{O}$ peak (8-9 $\mathrm{g} \mathrm{N}^{-1}$ day $\left.^{-1}\right)$ during March-

7 April, after the first tillage operation and before sowing of corn. In the corn production season during

8 April-September in 2011, significance correlation was obtained between measured and simulated

$9 \quad \mathrm{~N}_{2} \mathrm{O}$ fluxes, but the model overestimated $\mathrm{N}_{2} \mathrm{O}$ emissions over the corn season (Fig. 9 and Table 4).

10 The model simulated a moderately high $\mathrm{N}_{2} \mathrm{O}$ peak after the first fertilization event in early May, but

11 no such peak was observed in the measurements. There were some small negative measured peaks

$12\left(>-1.2 \mathrm{~g} \mathrm{~N} \mathrm{ha}^{-1} \mathrm{day}^{-1}\right)$ during July-September, but no negative $\mathrm{N}_{2} \mathrm{O}$ flux was found in the simulation.

13 Overall, in the wheat growing period from November 2011 to July 2012, the model successfully

14 simulated $\mathrm{N}_{2} \mathrm{O}$ emissions, but correlation between measured and simulated flux values was low (Fig.

159 and Table 4). There were three simulated $\mathrm{N}_{2} \mathrm{O}$ peaks after three $\mathrm{N}$-fertilization events in wheat

16 seasons, but no peak was observed after the third fertilization event in measurements. In contrast, the

17 model was inefficient in capturing two measured $\mathrm{N}_{2} \mathrm{O}$ peaks during winter before the first

18 fertilization event. Some small negative measured fluxes were found in measurements during wheat

19 growing season, mostly in late winter to early summer, but the model did not simulate any negative

$20 \mathrm{~N}_{2} \mathrm{O}$ flux during the same time. There were some interesting $\mathrm{N}_{2} \mathrm{O}$ flux activities in 2012 during the

21 fallow period between harvesting of wheat in July and sowing of barley in October. During this

22 fallow period, some positive and negative fluxes in the range -8 to $11 \mathrm{~g} \mathrm{~N} \mathrm{ha}^{-1}$ day $^{-1}$ were observed in

23 measurements, but DailyDayCent was unable to simulate them both precisely, where the model

24 underestimated the flux during late-summer, but overestimated during early autumn (Fig. 9). 
DailyDayCent was also unable to predict $\mathrm{N}_{2} \mathrm{O}$ uptake in the fallow period, unlike the measurements.

2 Significant correlation between measured and simulated $\mathrm{N}_{2} \mathrm{O}$ fluxes was obtained over the barley 3 growing period from October 2012 to July 2013, but the model significantly underestimated $\mathrm{N}_{2} \mathrm{O}$

4 emissions in the same period (Fig. 9 and Table 4). N-fertilizer was applied twice in the barley 5 season, and the model reasonably simulated the timing and magnitude of the measured peak after the 6 first fertilization, but underestimated the measured peak after the second fertilization event. A few 7 other discrepancies between simulated and measured $\mathrm{N}_{2} \mathrm{O}$ fluxes were also observed during the 8 barley production season (Fig. 9). For example, the model failed to simulate two small measured $9 \quad \mathrm{~N}_{2} \mathrm{O}$ peaks during winter. The model was also unable to simulate any measured peak $(\sim 10-60 \mathrm{~g} \mathrm{~N}$ $10 \mathrm{ha}^{-1}$ day $^{-1}$ ) during May-June before the harvesting of barley, where the model mostly underestimated 11 measured large $\mathrm{N}_{2} \mathrm{O}$ fluxes. There was a fallow period after harvesting of barley in July, 2013 until 12 February, 2014. The model predicted $\mathrm{N}_{2} \mathrm{O}$ emissions satisfactorily during this fallow period, but there was some underestimation in August and November, and overestimation in September (Fig. 9). Both in mown-grassland and grain-cropland, overall $\mathrm{N}_{2} \mathrm{O}$ peaks were driven by precipitation and fertilization events, and the main simulated and measured $\mathrm{N}_{2} \mathrm{O}$ peaks were seen during the main 16 plant growing period from spring-early autumn, whereas emissions were low in winter. Over a

17 period of three years, simulated cumulative $\mathrm{N}_{2} \mathrm{O}$ emissions were 5.90 and $3.72 \mathrm{~kg} \mathrm{~N} \mathrm{ha}^{-1}$ in grassland 18 and cropland, respectively (Figure 9). This indicates an annual $\mathrm{N}_{2} \mathrm{O}$ emission of 1.97 and $1.24 \mathrm{~kg} \mathrm{~N}$ $19 \mathrm{ha}^{-1}$ year $^{-1}$ from mown-grassland and grain-cropland, respectively. Results also showed that 20 simulated daily and cumulative $\mathrm{N}_{2} \mathrm{O}$ emissions from grassland were $59 \%$ greater compared to 21 cropland.

Model simulations of $\mathrm{N}_{2} \mathrm{O}$ emissions, WFPS, soil temperature, plant production and soil mineral $\mathrm{N}$ concentrations were examined for their sensitivities to a total of 14 parameters. In this 
section, model sensitivity is described as averaged over mown-grassland and grain-cropland, and then simulation sensitivity is compared between the two contrasting agro-systems.

Among the 14 parameters, DailyDayCent was mostly sensitive to four soil properties (BD, FC, SOC and $\mathrm{pH}$ ), amount of applied fertilizer-N, one soil $\mathrm{N}$-dynamics parameters in the “sitepar.in" file ( $\mathrm{N}_{2}$ Oadjust_fc) and two climatic inputs (air temperature and precipitation) (Table 5). Among different model output variables, WFPS was highly sensitive to changes in FC and BD, whereas sensitivity was lower to other parameters. Simulated soil temperature was only moderately sensitive to air temperature. DailyDayCent exhibited a low sensitivity in simulation of plant yield to different parameters viz. SOC, FC, fertilizer-N quantity, air temperature and precipitation. Model prediction of soil $\mathrm{NH}_{4}{ }^{+}$concentration was highly sensitive to changes in $\mathrm{BD}$ and $\mathrm{pH}$, whereas the same had a moderate sensitivity to fertilizer-N quantity, SOC and air temperature. In contrast, model simulation of soil $\mathrm{NO}_{3}{ }^{-}$concentration had high sensitivity to changes in fertilizer-N quantity and $\mathrm{BD}$, with a lower sensitivity to changes in air temperature, precipitation and SOC. Sensitivity of simulated $\mathrm{N}_{2} \mathrm{O}$ emissions was high to changes in BD and FC, moderate to SOC, $N_{2}$ Oadjust $f c$ and air temperature, and weak to fertilizer-N and daily precipitation. A change in air temperature by $\pm 1^{\circ} \mathrm{C}$ resulted in changes in simulated plant production, soil temperature, $\mathrm{NH}_{4}{ }^{+}$and $\mathrm{NO}_{3}{ }^{-}$ concentration, and $\mathrm{N}_{2} \mathrm{O}$ emissions by $1.6,6.9,7.9,3.7$ and $7.2 \%$, respectively. Similarly, changing daily precipitation by $\pm 10 \%$ altered simulated plant production, WFPS, $\mathrm{NH}_{4}^{+}$and $\mathrm{NO}_{3}{ }^{-}$ concentration, and $\mathrm{N}_{2} \mathrm{O}$ by $1.3,2.0,1.3,4.2$ and $4.1 \%$, respectively. Effects of an increase in air temperature were positive on soil temperature, soil $\mathrm{NO}_{3}{ }^{-}$concentration and $\mathrm{N}_{2} \mathrm{O}$ emissions, but negative on soil $\mathrm{NH}_{4}^{+}$concentration and plant production. On the other hand, decreasing daily precipitation had negative effects on WFPS, plant production and $\mathrm{N}_{2} \mathrm{O}$ emissions, but increased soil mineral $\mathrm{N}$ concentrations. Increasing $\mathrm{FC}$ by $10 \%$ led to an increase in simulated WFPS and $\mathrm{N}_{2} \mathrm{O}$ emissions by 10.5 and $17.2 \%$, respectively. Similarly, decreasing BC by $10 \%$ led to a decrease in 
WFPS and $\mathrm{N}_{2} \mathrm{O}$ emissions by 9.9 and $16.5 \%$. A $10 \%$ decrease in BD increased soil mineral $\mathrm{N}$

2 concentrations by 10.6-11.8\%, but decreased WFPS and soil mineral N concentration by 10.2 and

$315.0 \%$, respectively. Increasing the baseline SOC level by $10 \%$ led to an increase in crop production

4 (4\%), soil $\mathrm{NH}_{4}{ }^{+}$concentration (6.4\%), soil $\mathrm{NO}_{3}{ }^{-}$concentration (3.9\%) and $\mathrm{N}_{2} \mathrm{O}$ emissions $(9.2 \%)$,

5 whereas decreasing baseline SOC level by an equal magnitude decreased equally the crop

6 production $(4.1 \%)$, soil $\mathrm{NH}_{4}^{+}$concentration $\left(6.1 \%\right.$ ), soil $\mathrm{NO}_{3}{ }^{-}$concentration (3.7\%) and $\mathrm{N}_{2} \mathrm{O}$

7 emissions $(8.8 \%)$. A one unit increase in soil $\mathrm{pH}$ from 6.4 to 7.4 led to $4.7 \%$ decrease in soil $\mathrm{NH}_{4}^{+}$

8 concentration, whereas a one unit decrease in soil $\mathrm{pH}$ from 6.4 to 5.4 led to 3 times greater increase

9 in soil $\mathrm{NH}_{4}^{+}$concentration (19.7\%). Interestingly, there was no significance impact of change in soil

$10 \mathrm{pH}( \pm 1$ unit $)$ on other model simulations, including $\mathrm{N}_{2} \mathrm{O}$ emissions. Increasing fertilizer-N

11 application by $10 \%$ resulted in an increase in crop production, soil $\mathrm{NH}_{4}{ }^{+}$, soil $\mathrm{NO}_{3}{ }^{-}$concentration

12 and $\mathrm{N}_{2} \mathrm{O}$ emissions by $3.1,9.2,11.3$ and $4.8 \%$, respectively. On the other hand, decreasing fertilizer-

$13 \mathrm{~N}$ application by $10 \%$ decreased those model simulations by similar respective levels.

When mown-grassland system was compared with grain-cropland, model sensitivity was

15 found, in general, to be nearly equal under both systems, but a few differences were seen. For example, simulated hay production was insensitive to baseline SOC and N-fertilizer, but changing

17 both parameters by $10 \%$ altered grain-crop production by $3-4 \%$. Simulated crop yield was $10 \%$ more sensitive to temperature than hay production, and the negative effect of increase in air temperature

19 was greater on crop yield compared to hay production. Sensitivity of simulated soil $\mathrm{NO}_{3}{ }^{-}$ 20 concentration was greater to air temperature by 3.5 times and SOC by 1.1 times in cropland 21 compared to mown-grassland. Finally, $\mathrm{N}_{2} \mathrm{O}$ emissions were 1-1.6 times greater sensitive to SOC, air 22 temperature and BD in cropland compared to grassland.

All the above 14 parameters were also examined for their influence on model performances, 24 along with sensitivity analysis (Table 5). A $10 \%$ decrease in FC or BD led significant 
underestimation for WFPS in mown-grassland. Similarly, decreasing air temperature input variable

2 by $1^{\circ} \mathrm{C}$ resulted in significance underestimation for soil temperature in grassland. Changes in daily

3 air temperature $\left(1^{\circ} \mathrm{C}\right)$, precipitation, $\mathrm{FC}, \mathrm{SOC}$ and fertilizer-N quantity $(10 \%)$ altered significantly

4 model performances for soil $\mathrm{NO}_{3}{ }^{-}$concentration in grassland (Table 5). On the other hand, changing

5 air temperature and soil $\mathrm{pH}$ by $\pm 1^{\circ} \mathrm{C}$ and \pm 1 unit, respectively, or changing other parameters by $10 \%$

6 did not influence model performance for simulation of $\mathrm{N}_{2} \mathrm{O}$ emissions, but they had potentials to

7 reduce simulation errors to some extent.

\section{General Discussion}

\subsection{Testing model performance}

Use of dynamic system models for simulation of $\mathrm{N}_{2} \mathrm{O}$ emission has increased rapidly in recent years. These models are now being used not only for prediction of $\mathrm{N}_{2} \mathrm{O}$ emissions from different agro-ecosystems, but estimation of $\mathrm{N}_{2} \mathrm{O}$ inventories on national, regional and global scales, and assessing climate change impacts and mitigation strategies (Del Grosso et al., 2006, 2009; EPA, 2006). However, to ensure that these model predictions are reliable enough in a new environment, model performance needs to be tested first with different data streams from real world experiments. To our knowledge, the present study is one of the first of its kind to rigorously test the DailyDayCent model against high frequency field measurements for not only daily $\mathrm{N}_{2} \mathrm{O}$ emission, but also for daily soil water (WFPS) and soil temperature, including SOC, plant production and soil mineral nitrogen concentration at different temporal frequency, over a relatively long time period (three years) in two contrasting ecosystems together viz. mown-grassland and grain-cropland.

The model DailyDayCent simulates nitrification as a function of soil $\mathrm{NH}_{4}{ }^{+}$concentration, water content, temperature and $\mathrm{pH}$; whereas the model assumes denitrification is a function of $\mathrm{NO}_{3}{ }^{-}$ 
concentration ( $e^{-}$acceptor), labile $\mathrm{C}$ availability ( $e^{-}$donor) and $\mathrm{O}_{2}$ availability (competing $e^{-}$ acceptor), where $\mathrm{O}_{2}$ availability is calculated as a function of WFPS, $\mathrm{O}_{2}$ demand and soil properties that control gas diffusivity (Parton et al., 2001; Del Grosso et al., 2008b). For the above reasons, as correct simulations of WFPS, soil temperature, plant production, SOC and soil mineral $\mathrm{N}$ concentration are a prerequisite for successful model simulation of $\mathrm{N}_{2} \mathrm{O}$ emissions (Del Grosso et al., 2011), model performance for WFPS, soil temperature, plant production SOC, soil mineral $\mathrm{N}$ and at last $\mathrm{N}_{2} \mathrm{O}$ emissions are discussed below.

\subsubsection{Modelling water filled pore space and soil temperature}

In the present study, the DailyDaycent simulated WFPS and soil temperature efficiently in mowngrassland, although some minor discrepancies were found in individual seasons. Model performance for WFPS and soil temperature in cropland was not tested due to unavailability of measurements. However, model simulations of WFPS and soil temperature in croplands were different to those for mown-grassland, probably due to the different plant growth and management practices. As mowngrassland and grain-cropland were in adjacent fields, with very similar soil characteristics, and almost the same model parameterization was used for both (except plant and management practices), a similarly efficient model performance for WFPS and soil temperature was expected in the graincropland. Some studies obtained accurate predictions of soil water and temperature (Del Grosso et al., 2008a; Jarecki et al., 2008; Scheer et al., 2014), though a few others found some discrepancy in simulation of WFPS during winter and summer due to the way in which internal drainage and hysteresis effects are simulated in the model, dew formation in summer, and accumulation, drifting and melting of snow, which are not accounted for in the model (Parton et al., 2001; Del Grosso et al., 2002; Stehfest and Müller, 2004). However, correct estimation of FC was found to be one of the most critical factors for the successful simulation of WFPS in our study. 
2 The simulated plant growth curves were reasonable (Fig. 6), and good agreements between 17 residue decomposition. measured and simulated hay production, and overall crop yield were obtained in the present experiment. DailyDayCent has been successfully applied for simulation of plant production across grain-croplands and grassland (Stehfest et al., 2007; Del Grosso et al., 2008a; Abdalla et al., 2010; Lee et al., 2012; Chang et al., 2013). However, the model significantly underestimated plant production for corn in our study. In our present experiment, only $36 \mathrm{~kg}$ fertilizer-N was applied during the corn season. Most of the $\mathrm{N}$ demand, as estimated by PC-AZOTE for corn, was supposedly met through decomposition of grass biomass incorporated at the time of ploughing before sowing of corn in spring 2011, during the land-use conversion from mown-grassland to graincropland. However, a minimum dose of $\mathrm{N}$-fertilizer at the rate of $110 \mathrm{~kg} \mathrm{~N}^{-1}$ is quite common in the study region (Kunrath et al., 2015). One additional model simulation with the above minimum $\mathrm{N}$-fertilization, keeping all other inputs the same as the original model simulation, produced favourable results for corn production, with no significant effect on overall $\mathrm{N}_{2} \mathrm{O}$ emission (Table 4). Thus, our results demonstrate that the corn production was most probably limited by $\mathrm{N}$-deficiency within the model, indicating inability of the model to precisely simulate plant available $\mathrm{N}$ from plant

\subsubsection{Modelling soil organic carbon and soil mineral nitrogen}

Reasonable agreements between measured and modelled SOC stocks indicate that the baseline SOC and its dynamic were simulated reasonably in our experimental site as recommended by the model developer. The carbon sub-model of DailyDaycent is based on the Century model, and the family of models is well known for their good capacity to simulate SOC dynamics (Chang et al., 2013; Congreves et al., 2015; Xuan et al., 2016). Regarding modelling soil mineral $\mathrm{N}$ at the site, simulation of soil $\mathrm{NH}_{4}^{+}$concentration was close, but the model significantly underestimated soil $\mathrm{NO}_{3}{ }^{-}$ 
concentration in both the systems. A similar underestimation of soil $\mathrm{NO}_{3}^{-}$level by the DailyDayCent model was found by other studies (Del Grosso et al., 2008a; Jarecki et al., 2008). Systematic significant disagreements between measured and modelled soil mineral $\mathrm{N}$ is an issue with the present model, and various studies have reported similar concern when using the model (Parton et al., 2001; Stehfest and Müller, 2004; Del Grosso et al., 2008a; Jarecki et al., 2008; Scheer et al., 2014), even after site specific calibration (Necpálová et al., 2015). Systematic discrepancy between measured and simulated soil mineral $\mathrm{N}$ is an issue for different ecosystem models, such as the CoupModel (Conrad and Fohrer, 2009), DNDC (Smith et al., 2008), and EPIC, NLEAP, NTRM and CERES (Beckie et al., 1995). Reasonable simulation of soil $\mathrm{NH}_{4}{ }^{+}$concentration, but underestimation of $\mathrm{NO}_{3}{ }^{-}$in the present study with DailyDayCent indicates some discrepancy in nitrification/denitrification process within the model, for example a lower nitrification rate, or overestimation of denitrification rate, or some direct but significant loss of $\mathrm{NO}_{3}{ }^{-}$from soil. $\mathrm{As}_{2} \mathrm{O}$ flux is calculated by the model from simulated aggregated flux of $\mathrm{N}_{2}+\mathrm{N}_{2} \mathrm{O}$ and an $\mathrm{N}_{2} / \mathrm{N}_{2} \mathrm{O}$ ratio adjustment coefficient (n2n2oadj), a greater sensitivity of $\mathrm{N}_{2} \mathrm{O}$ emissions to $n 2 n 2 o a d j$ along with an overall incorrect simulation of $\mathrm{N}_{2} \mathrm{O}$ emissions could contribute to the possible under/overestimation of nitrification/denitrification process. However, the overall satisfactory simulation of $\mathrm{N}_{2} \mathrm{O}$ emission and the insensitivity of simulated $\mathrm{N}_{2} \mathrm{O}$ emissions to the parameter ' $\mathrm{n} 2 \mathrm{n} 2 \mathrm{oadj}$ ' do not support the hypothesis that nitrification was underestimated or that denitrification rate was overestimated. One reason for poor model performance for soil $\mathrm{NO}_{3}{ }^{-}$concentration in the present experiment could be inappropriate model simulation of leaching loss of soil $\mathrm{N}$. The testing of DailyDayCent for $\mathrm{N}$ leaching has been relatively limited (Stehfest and Müller, 2004; Del Grosso et al., 2005). Annual simulated N-leaching from the mown-grassland was 2.2 times higher compared to cropping system. Leaching loss of $\mathrm{N}$ was not measured in our present experiment, but from the similar adjacent experiments, Kunrath et al. (2015) reported in contrast an annual leaching loss of $\mathrm{N}$ form the 
cropping system 3-4 times greater than grassland. Applied annual fertilizer-N in our grassland was 1.2 times higher compared to the cropland, but simulated similar annual N-uptake in both systems might provide a lager excess $\mathrm{N}$ in mown-grassland, and this excess $\mathrm{N}$ could be lost through leaching. Successful simulations of plant productions in the present study indicate reliable simulation of plant N-uptake, whereas Kunrath et al. (2015) used a simple computational procedure for estimating annual leaching loss of $\mathrm{N}$ from qualitative measurements, without capturing other components of $\mathrm{N}$ cycle. However, contrasting results on N-leaching suggest the need for more field experiments, model testing and subsequent model development for correct simulation of leaching loss of $\mathrm{N}$ and soil $\mathrm{NO}_{3}{ }^{-}$concentration. Surprisingly in our sensitivity analysis, none of the soil N-dynamics parameters in "sitepar.in" file influenced significantly, nor improved, the model performance for simulation of soil $\mathrm{NO}_{3}{ }^{-}$concentration. Thus, concentration of simulated soil $\mathrm{NO}_{3}{ }^{-}$was relatively insensitive to variation in soil N-dynamics parameters in "sitepar.in" file within the model structure. Necpálová et al. (2015) observed the inability of an inverse modelling algorithm to improve simulation of soil $\mathrm{NO}_{3}{ }^{-}$, when the same improved model performance for other components of $\mathrm{N}$ cycle, and concluded that the poor performance of the DailyDayCent model for soil mineral $\mathrm{N}$ is probably due to the result of excessively restrictive parameter constraints within the model parameterization, or that the model structure simply does not allow accurate simulation of the observed phenomenon due to some model structural error. Thus, the current exercise suggests that the DailyDayCent sub-model responsible for $\mathrm{N}$ transformations might need to be improved for a better simulation of soil mineral $\mathrm{N}$, particularly soil $\mathrm{NO}_{3}{ }^{-}$concentration.

\subsubsection{Modelling overall $\mathrm{N}_{2} \mathrm{O}$ emissions}

When DailyDayCent was tested for the simulation of the overall daily $\mathrm{N}_{2} \mathrm{O}$ emission, significant correlations between measured and simulated $\mathrm{N}_{2} \mathrm{O}$ fluxes were found over the entire experimental period, both in mown-grassland $(r=0.63)$ and grain-cropland $(r=16)$. Although the 
correlation was much lower in cropland, but was still statistically significant at $P<0.05$. Results of the present experiment demonstrate that the model has the ability to simulate significantly the overall dynamics of the daily $\mathrm{N}_{2} \mathrm{O}$ flux in contrasting agroecosystems. Different studies with the same model have found a range of correlations from weak to strong $(r \sim 0-0.72)$ across different agroecosystems. Parton et al. (2001) found correlation between daily measured vs. simulated $\mathrm{N}_{2} \mathrm{O}$ emissions, ranging from 0 to 0.44 , from a variety of five different grassland sites in the United States. Scheer et al. (2014) obtained a better correlation $(r=0.72)$ from a cotton-wheat crop rotational experiment. When analysing total simulation error for modelling daily $\mathrm{N}_{2} \mathrm{O}$ emissions over the entire experimental period, no significant error was obtained under grain-cropping, but significant simulation error (RMSE) was found at the 95\% confidence limit in mown-grassland. However, $M E$ was not significant at $P<0.025$, thus model performance was considered reasonable for the mown-grassland, when mean daily measurements of $\mathrm{N}_{2} \mathrm{O}$ flux were used. However, when the measurement error generated from spatial replications was accounted for, simulation error (RMSE) became significant. Thus, our result supports the view that high spatial variation in measured data of $\mathrm{N}_{2} \mathrm{O}$ flux, or uncertainties inherent in measurements, can contribute to apparent poor model performance (Del Grosso et al., 2001; Rafique et al., 2014). Different studies demonstrate that performance of the DailyDayCent model for $\mathrm{N}_{2} \mathrm{O}$ emissions decreases when model performance is tested against daily measured flux, instead of cumulative seasonal or annual emissions (Parton et al., 2001; Del Grosso et al., 2002, 2008a, 2008b, 2011; Abdalla et al., 2010). Other ecosystem models also face similar difficulties in simulation of daily $\mathrm{N}_{2} \mathrm{O}$ emissions (Yeluripati et al., 2015). Different studies demonstrated model performance for overall daily $\mathrm{N}_{2} \mathrm{O}$ emissions from poor to reasonable using different models including DailyDayCent (Smith et al., 2002, 2008; Del Grosso et al., 2008; Jarecki et al., 2008; Abdalla et al., 2010; van Oijen et al., 2011; Rafique et al., 2013; He et al. 2016). In our present study, overall reasonable model performance was obtained for modelling daily $\mathrm{N}_{2} \mathrm{O}$ 
emissions in mown-grassland and grain-cropland. Recently, similar overall favourable performance for daily $\mathrm{N}_{2} \mathrm{O}$ emission was obtained by Scheer et al. (2014) from a cotton-wheat cropping system in Australia. Scheer et al. (2014) explained their overall successful model simulation for $\mathrm{N}_{2} \mathrm{O}$ emissions by the high-frequency data set, used for initial model calibration and model testing, whereas we found overall good model performance for the same due to the ability of the DailyDayCent model to successfully simulate WFPS, soil temperature, SOC, plant production and soil mineral $\mathrm{N}$, particularly $\mathrm{NH}_{4}{ }^{+}$, which all together control nitrification and denitrification processes directly or indirectly. Our results demonstrate that DailyDayCent has potential for successfully simulating overall daily $\mathrm{N}_{2} \mathrm{O}$ emissions in different agro-ecosystems in the study region, and the model would be a good tool for projection of $\mathrm{N}_{2} \mathrm{O}$ emissions under different management and climate change scenarios, and evaluation of different mitigation strategies for overall $\mathrm{N}_{2} \mathrm{O}$ emission.

The simulated annual $\mathrm{N}_{2} \mathrm{O}$ emissions of the present study viz. 1.24-1.97 $\mathrm{kg} \mathrm{N}^{-1} \mathrm{yr}^{-1}$ with applied fertilizer- $\mathrm{N} 95-210 \mathrm{~kg} \mathrm{~N} \mathrm{ha}^{-1} \mathrm{yr}^{-1}$, were within the range of measured emissions of 0.65-2.9 $\mathrm{kg} \mathrm{N} \mathrm{ha}{ }^{-1} \mathrm{yr}^{-1}$ as reported by other researchers from similar agro-ecosystems around France (Gabrielle et al., 2006; Laville et al., 2011). Annual $\mathrm{N}_{2} \mathrm{O}$ emissions from our managed grassland and cropland were also in line with different studies in other European countries (1-3.9 $\left.\mathrm{kg} \mathrm{N} \mathrm{ha}^{-1} \mathrm{yr}^{-1}\right)$, depending on the quantity of applied fertilizer- $\mathrm{N}\left(0-350 \mathrm{~kg} \mathrm{~N} \mathrm{ha}^{-1} \mathrm{yr}^{-1}\right.$ ) (Abdalla et al., 2010; Fitton et al., 2014b). A greater range of $\mathrm{N}_{2} \mathrm{O}$ emissions from $2-35 \mathrm{~kg} \mathrm{~N} \mathrm{ha}^{-1} \mathrm{yr}^{-1}$ was also found around the world, but with a higher $\mathrm{N}$-fertilization of 135-432 $\mathrm{kg} \mathrm{N} \mathrm{ha}^{-1} \mathrm{yr}^{-1}$ (Cardenas et al., 2010; Rafique et al., 2011; Abdalla et al., 2014). In general, $\mathrm{N}_{2} \mathrm{O}$ emissions from agricultural systems have been found to increase with increasing N-input, either linearly (Flechard et al., 2007; Beek et al., 2009) or exponentially (Eckard et al., 2006; Rafique et al., 2011). The positive correlation of $\mathrm{N}_{2} \mathrm{O}$ emissions with the quantity of applied N, and a $120 \%$ greater application of N-fertilizer could explain the $59 \%$ higher $\mathrm{N}_{2} \mathrm{O}$ emissions from the mown-grassland system compared to the grain-cropping. In the 
present experiment, averaged simulations of WFPS and soil temperature were greater by $4.5 \%$ and

$2 \quad 1^{\circ} \mathrm{C}$, respectively in grain-cropland compared to mown-grassland, but soil mineral $\mathrm{N}$ concentrations

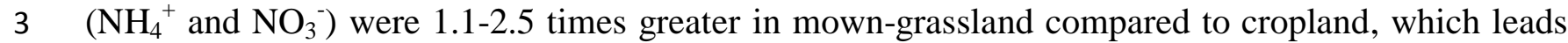

4 to higher $\mathrm{N}_{2} \mathrm{O}$ emissions from mown-grass than grain cropping system.

\subsubsection{Modelling $\mathrm{N}_{2} \mathrm{O}$ emissions on day-by-day basis}

High frequency measurements in the present study provided the opportunity to analyse in detail the performance of the model for $\mathrm{N}_{2} \mathrm{O}$ emissions on a daily basis. Some inconsistencies were found under both mown-grassland and grain-cropland. Although, most of the discrepancies between measured and model simulation of $\mathrm{N}_{2} \mathrm{O}$ flux were found after a precipitation or $\mathrm{N}$-fertilization event, no definite pattern was obtained over the course of the three year experiment. In the present simulation, discrepancies between measured and modelled $\mathrm{N}_{2} \mathrm{O}$ flux were found mainly in five categories viz. a) the model failed to capture some large $\mathrm{N}_{2} \mathrm{O}$ fluxes, b) the model simulated some peaks that were not found in the measurements, c) the model failed to simulate some measured peaks, d) general underestimation of large fluxes, but overestimation of small fluxes and e) some negative $\mathrm{N}_{2} \mathrm{O}$ fluxes, observed in the measurements that were not found in the simulation. DailyDayCent was unable to simulate some large measured $\mathrm{N}_{2} \mathrm{O}$ peaks both in mown-grassland (150-250 $\left.\mathrm{g} \mathrm{N} \mathrm{ha}^{-1} \mathrm{day}^{-1}\right)$ and grain-cropland ( 10-60 $\mathrm{g} \mathrm{N} \mathrm{ha}^{-1}$ day $\left.^{-1}\right)$ during June, 2013. One possible reason for this could be the slight underestimation of WFPS by the model during the month June in 2013 (Fig. 4). However, underestimation of WFPS alone could not explain the inability of the model to capture large $\mathrm{N}_{2} \mathrm{O}$ peaks, as model underestimation of WFPS was merely XX\%. Another possible reason could be the inability of the model to carry over the residual mineral $\mathrm{N}$ from previous $\mathrm{N}$ fertilizer applications (90-150 $\mathrm{kg} \mathrm{N} \mathrm{ha}^{-1}$ ) during February-April in the same year. A similar phenomenon with the same model was observed by other researchers (Abdalla et al., 2010). Other explanations could be the systematic underestimation of soil $\mathrm{NO}_{3}{ }^{-}$in our experiments or the 
description of $\mathrm{N}$ transformation processes in the model or structural error in the model (Smith et al., 2008, van Oijen et al. 2011). Similar weaknesses of the DailyDayCent model in capturing large $\mathrm{N}_{2} \mathrm{O}$ peaks have been reported in different studies (Del Grosso et al., 2008a; Rafique et al., 2013; Necpálová et al., 2015). Inability to simulate very large, infrequent $\mathrm{N}_{2} \mathrm{O}$ peaks is also common across other ecosystem models. For example, van Oijen et al. (2011) found that no model, even after calibration, explained infrequent events of very high nitrogenous emission rate when applying a set of four models with different complexity viz. BASFOR, DayCent, Mobile-DNDC and CoupModel. Regarding simulation of extra $\mathrm{N}_{2} \mathrm{O}$ peaks in our experiment, Del Grosso et al. (2008a) also found similar extra peaks what were not observed in their measurements. As in the present experiment, Jarecki et al. (2008) and Del Grosso et al. (2008a) also found similar underestimation and overestimation of $\mathrm{N}_{2} \mathrm{O}$ flux by the DailyDayCent model at high and low ranges, respectively. Thus, simulation of $\mathrm{N}_{2} \mathrm{O}$ flux on a day-by-day basis is a concern with the DailyDayCent model (Parton et al., 2001; Del Grosso et al., 2002, 2005; Jarecki et al., 2008; Rafique et al., 2013). The poor model performance for $\mathrm{N}_{2} \mathrm{O}$ flux on day-to-day basis is a common concern for most process-based models. Most ecosystem models commonly simulate total or overall $\mathrm{N}_{2} \mathrm{O}$ emissions correctly, or at least reasonably, but inaccuracy in the timing of emissions and over/under-estimations of individual $\mathrm{N}_{2} \mathrm{O}$ peaks are common concerns with different models, for example DNDC (Smith et.al, 2002, 2008), CERES (Gabrielle et al, 2006), PaSim (Calanca et al. 2007) and CoupModel (Hongxing et. al 2016). There could be several reasons for the overall systematic disagreements for DailyDayCent model in simulation of daily $\mathrm{N}_{2} \mathrm{O}$ emissions. These disparities could not be explained by poor model performance, or any small simulation discrepancy for WFPS, soil temperature, SOC, soil $\mathrm{NH}_{4}{ }^{+}$ concentration, or plant production ( $\mathrm{N}$-uptake) in our experiments - unlike in other studies (Parton et al., 1998; Del Grosso et al., 2002; Stehfest and Müller, 2004; Scheer et al., 2014), as the dynamics of those variables were simulated by the model correctly, or at least reasonably well, in the present 
experiment. Additionally, no regular pattern was found in those day-to-day $\mathrm{N}_{2} \mathrm{O}$ flux discrepancies, unlike some regular but minor seasonal simulation discrepancies obtained in simulation of some of the above variables. Significant difference between predicted and measured soil $\mathrm{NO}_{3}{ }^{-}$concentrations, as found in our study, could be a possible factor. The current exercise suggests that the DailyDayCent sub-module responsible for $\mathrm{N}$ transformations might need to be improved for a better simulation of soil mineral $\mathrm{N}$, as discussed earlier, and also for better simulation of $\mathrm{N}_{2} \mathrm{O}$ emissions on a daily basis. Similar conclusions have also been drawn in other studies (Stehfest and Müller, 2004; Del Grosso et al., 2008a; Jarecki et al., 2008; Necpálová et al., 2015). For simulation of soil mineral $\mathrm{N}$ and $\mathrm{N}_{2} \mathrm{O}$ emissions with higher precision and accuracy, overall improvement in model algorithms and parameterization controlling nitrification and denitrification processes, modifications in the nitrification and denitrification subroutines, and improvement in the model structure could be beneficial(Jarecki et al., 2008; Del Grosso et al. 2008a, 2010; van Oijen et al., 2011; Necpálová et al., 2015). Other reasons for model disagreement with measurements on a daily basis could be due to the local emission hot spots, which might be formed due to $\mathrm{N}$ deposition ( $\mathrm{N}$-fertilization), producing high peaks, which could perhaps be captured in measurements, but not by the model, as DailyDayCent assumes all the model inputs are uniform spatially (Del Grosso et al., 2008a). Emissions of $\mathrm{N}_{2} \mathrm{O}$ might also be influenced by heterogeneity of the soil surface, but spatial variation is a limitation of the model, as the model counts soil as a uniform system (Rafique et al., 2014). Effects of topography, aspect, wind, humidity, microsite heterogeneity, gas diffusion, and other factors on soil water and temperature, which are not included in DailyDayCent, could be also critical for precise simulation of $\mathrm{N}_{2} \mathrm{O}$ emissions on a daily basis (Del Grosso et al., 2005). The lack of depthdependence in the denitrifying microbial community and their composition are another limitation in the DailyDayCent model. Denitrification rates may vary with soil depth as denitrifying microbial biomass and their species composition vary with soil depth (Venterea et al., 2005; Paul, 2006). Thus, 
microbial biomass and species composition may be important controls for $\mathrm{N}_{2} \mathrm{O}$ emission in field

2 soils (Del Grosso et al., 2000). Del Grosso et al. (2008a) suggested that the model could be improved

3 by accounting for the impacts of soil depth-dependent changes in microbial community on

4 denitrification rate. The DailyDayCent model failed to simulate any of the observed negative fluxes

$5\left(\leq-8 \mathrm{~g} \mathrm{~N} \mathrm{ha}^{-1} \mathrm{day}^{-1}\right)$ in our experiment. The classical microbial denitrification pathway of

6 atmospheric $\mathrm{N}_{2} \mathrm{O}$ to $\mathrm{N}_{2}$ at the surface layer of soils could be an explanation to negative $\mathrm{N}_{2} \mathrm{O}$ flux or

$7 \quad \mathrm{~N}_{2} \mathrm{O}$ uptake by agricultural soils ( $\mathrm{Yu}$ et al., 2000; Wrage et al., 2004). Negative $\mathrm{N}_{2} \mathrm{O}$ fluxes have

8 been found in various agroecosystems across different seasons ranging from -1 to $-55 \mathrm{~g} \mathrm{~N} \mathrm{ha}^{-1}$ day $^{-1}$

9 (Flechard et al., 2005; Rafique et al., 2011; Zhang et al., 2013). In contrast, from a recent

10 investigation, Cowan et al., (2014) has suggested that the bulk of negative $\mathrm{N}_{2} \mathrm{O}$ fluxes reported from

11 agricultural fields are most likely due to instrument noise or limits in detection of a particular flux

12 measurement methodology, but not a result of microbiological activity consuming atmospheric $\mathrm{N}_{2} \mathrm{O}$.

13 However, it remains plausible that various microbial processes in soils are able to remove $\mathrm{N}_{2} \mathrm{O}$ from

14 the atmosphere under a range of aerobic and anaerobic soil conditions, but different influential

15 factors, the mechanisms, and the triggers for $\mathrm{N}_{2} \mathrm{O}$ uptake need to be studied further to understand

16 these factors and processes precisely (Wrage et al., 2001; Chapuis-Lardy et al., 2007). Because the

17 mechanism of soil uptake of $\mathrm{N}_{2} \mathrm{O}$ is unclear, the DailyDayCent model does not simulate the uptake

18 of $\mathrm{N}_{2} \mathrm{O}$. Although measured cumulative negative flux was small and the model simulated overall

$19 \mathrm{~N}_{2} \mathrm{O}$ emissions satisfactorily without the above $\mathrm{N}_{2} \mathrm{O}$ uptake mechanism, incorporation of the above

20 mechanism in the present model may be helpful to represent real world systems more precisely.

\subsection{Sensitivity analysis:}

Sensitivity analysis is important as it elucidates many aspects, importance and implications

23 for the present modelling study. For example, sensitivity analysis demonstrated that $\mathrm{N}_{2} \mathrm{O}$ emissions

24 from agricultural systems (mown-grass and grain-cropping) may increase by 5-13\% if air 
temperature increases by just $1{ }^{\circ} \mathrm{C}$ in the near future. In contrast, decreasing precipitation of $10 \%$ would decrease $\mathrm{N}_{2} \mathrm{O}$ emission by $4 \%$. Sensitivity analysis of the present study demonstrated that sensitivity of $\mathrm{N}_{2} \mathrm{O}$ emissions to changes in air temperature and precipitation is most likely the results of combined sensitivities of WFPS, soil temperature, plant production and soil mineral $\mathrm{N}$ concentrations, which control nitrification and denitrification processes. We tested the influence of an increase in air temperature and a decrease in precipitation uniformly throughout the year, whereas it is quite possible that future temperature increase or precipitation decrease would not be uniform throughout the year. In any case, increased $\mathrm{N}_{2} \mathrm{O}$ emissions due to future climate change could enhance climate change further. Our findings on sensitivity of $\mathrm{N}_{2} \mathrm{O}$ emissions to climate change are in the line to those of other researchers. Using the DailyDayCent model in a wheat experiment, UK, Fitton et al. (2014b) reported 6-17\% increases and 2-3\% decreases in annual $\mathrm{N}_{2} \mathrm{O}$ emissions due to an increase in temperature by $1{ }^{\circ} \mathrm{C}$ and decrease of daily precipitation by $1 \mathrm{~mm}$, respectively. Our results also show that an average error or uncertainty of $1^{\circ} \mathrm{C}$ or $10 \%$ in the inputs of average daily air temperature and precipitation, respectively, would not influence model performance significantly for at least $\mathrm{N}_{2} \mathrm{O}$ emissions. We found three out of six soil properties viz. FC, BD and SOC, were the most influential parameters in determining $\mathrm{N}_{2} \mathrm{O}$ emissions. A $10 \%$ change or uncertainty in these three parameters individually could introduce on an average 4-12\% error in simulated WFPS and soil mineral $\mathrm{N}$ concentration, and ultimately 9-17\% uncertainty in $\mathrm{N}_{2} \mathrm{O}$ emissions. In general, changing FC, BD and SOC influence $\mathrm{N}$ transformations by altering soil pore spaces, WFPS, oxygen demand, gas diffusivity, availability of soil mineral $\mathrm{N}$ and microbial activity; most of these processes are also accounted by DailyDayCent (Abbasi and Adams, 2000; Parton et al., 2001). Although $\mathrm{N}_{2} \mathrm{O}$ emissions were moderate to highly sensitive to FC, BD and SOC, a $10 \%$ error or uncertainty in these three soil properties did not influence model performance significantly for $\mathrm{N}_{2} \mathrm{O}$ emissions. But, a $10 \%$ error or uncertainty in these three parameters significantly changed the model performance 
for WFPS and soil mineral N concentration. Additionally a $10 \%$ reduction in error or uncertainty in measurement of $\mathrm{FC}, \mathrm{BD}$ and $\mathrm{SOC}$ has the potential to reduce simulation error to some extent also for $\mathrm{N}_{2} \mathrm{O}$ emissions (Table 5), hence these three parameters were considered as important for modelling $\mathrm{N}_{2} \mathrm{O}$ emissions. s Thus our results demonstrated the importance of measuring different soil properties correctly, particularly $\mathrm{FC}, \mathrm{BD}$ and SOC, for simulation of $\mathrm{N}_{2} \mathrm{O}$ emissions. Similar conclusions had also been reported by other studies (Abdalla et al., 2009; Fitton et al., 2014a). In the present study (soil $\mathrm{pH}$ (6.4), simulated soil $\mathrm{NH}_{4}{ }^{+}$concentration was highly sensitive to changes in soil $\mathrm{pH}$, and effect of one unit decrease in soil $\mathrm{pH}$ was greater compared to a one unit $\mathrm{pH}$ increase. However simulated soil $\mathrm{NO}_{3}{ }^{-}$concentration and $\mathrm{N}_{2} \mathrm{O}$ emissions were not sensitive to soil $\mathrm{pH}$. Fitton et al. (2014b) found $\mathrm{N}_{2} \mathrm{O}$ emissions to be most sensitive to soil $\mathrm{pH}$, and sensitivity was an order of magnitude greater compared to FC and $\mathrm{BD}$. They argued that a decrease of soil $\mathrm{pH}$ by 1 unit in their slightly acidic soils ( $\mathrm{pH} 6)$ might contribute to the movement of $\mathrm{C}$ and $\mathrm{N}$ through different pools, interaction between $\mathrm{pH}$ and low temperature, specific change in $\mathrm{N}$-compounds, and ultimately the creation of conditions favourable for denitrification. As $\mathrm{pH}$ is logarithmic, any effect of one unit increase in soil $\mathrm{pH}$ is not the same as a one unit decrease. For the same reason, effects of change in soil $\mathrm{pH}$ (increase/decrease) in different sites with different soil $\mathrm{pH}$ are not comparable. However, in the nitrification sub-module of DailyDayCent, soil $\mathrm{pH}$ directly influence nitrification rate, and there is no direct influence of the parameter on denitrification (Parton et al., 2001). Thus, high sensitivity of $\mathrm{N}_{2} \mathrm{O}$ emissions to soil $\mathrm{pH}$ may need to be investigated further using measurements and the model. Sensitivity analysis indicated that there might be some trade-offs between plant production and $\mathrm{N}_{2} \mathrm{O}$ emissions when changing baseline SOC levels. Our results indicated that increasing the baseline SOC by $10 \%$ would increase grain-crop yield by $4 \%$, but also may increase $\mathrm{N}_{2} \mathrm{O}$ emissions up to $12 \%$. Sensitivity analysis illustrated the possible scope for reducing $\mathrm{N}_{2} \mathrm{O}$ emissions by reducing the quantity of $\mathrm{N}$-fertilizer in mown-grasslands without any reduction in hay production, although doing 
the same in grain-cropping systems could reduce the crop yield. The results are explained by the yield saturation observed in hay production system, and an unsaturation in grain-crop yield. The scope for yield optimization with increasing $\mathrm{N}$-fertilizer in cropping system is narrow and would come at the cost of higher $\mathrm{N}_{2} \mathrm{O}$ emissions. However, as discussed earlier, DailyDayCent underestimated plant production only for corn, mainly due to the lower availability of simulated mineral $\mathrm{N}$ from mineralization of grass biomass incorporated during land use change from temporary grassland to grain-cropland just before sowing of corn. Taking the above facts into consideration, model performance with respect to plant production can be considered reasonable (Lemaire et al., 2008; Kunrath et al., 2015).

Sensitivity of model simulations to five soil $\mathrm{N}$ parameters in the 'sitepar.in' file was also tested in the present study. It is not generally recommended that these parameters be tuned arbitrarily to improve the model fit (Del Grosso et al., 2011). However, $\mathrm{N}_{2} \mathrm{O}$ emissions have been found to be highly sensitive to MaxNitAmtin recent studies (Rafique et al., 2013; Necpálová et al., 2015). In contrast, $\mathrm{N}_{2} \mathrm{O}$ emissions were not seen to be sensitive to MaxNitAmt in our study. The former two studies were complex inverse modelling studies, with data assimilation/optimization to determine the optimized values of the parameter ranging from $0.28-1.91 \mathrm{~g} \mathrm{~N} \mathrm{~m}^{-2}$. In our study, the default parameter value of $0.4 \mathrm{~g} \mathrm{~N} \mathrm{~m}^{-2}$ was used, and the sensitivity analysis tested one parameter at a time, keeping other parameters constant. According to the developer, users should not use parameter values in DailyDayCent that improve model performance unless they make sense biologically. However, as our present study demonstrated an insensitivity of $\mathrm{N}_{2} \mathrm{O}$ emissions to MaxNitAmt, ; further experiments may be needed to examine the above parameter value and its sensitivity. In the older version of the DailyDayCent model, only one parameter was used to control the proportion of nitrified $\mathrm{N}$ that is lost as $\mathrm{N}_{2} \mathrm{O}$ (nitrified_n), and different studies demonstrated low to medium sensitivity of $\mathrm{N}_{2} \mathrm{O}$ emissions to the parameter (Rafique et al., 2013; Rafique et al., 2014; Necpálová 
et al., 2015). The model developer also observed similar results, and recommend that a relationship may need to be developed to predict the above proportion based on the $\mathrm{O}_{2}$ availability or other variables (Del Grosso et al., 2008a). In the new version of the DailyDayCent, the same proportion is controlled by two different parameters, $N_{2}$ Oadjust $f_{-}$i.e. the maximum proportion of nitrified $\mathrm{N}$ that is lost as $\mathrm{N}_{2} \mathrm{O}$ at field capacity, and $\mathrm{N}_{2}$ Oadjust_wp i.e. the minimum proportion of nitrified $\mathrm{N}$ that is lost as $\mathrm{N}_{2} \mathrm{O}$ at wilting point (). However, only $\mathrm{N}_{2}$ Oadjust_fc was found to be a critical parameter, as $\mathrm{N}_{2} \mathrm{O}$ emissions were sensitive to it in our study, and the results also pointed out that the default values of these soil $\mathrm{N}$-dynamics parameters in "sitepar.in" file might need site-specific calibration for a better model simulation of $\mathrm{N}_{2} \mathrm{O}$ emissions from different agricultural systems. Our results show that overall model sensitivity was slightly different between mown-grassland and grain-cropland. The main reasons for this difference could be the different management practices (e.g. tillage vs. mowing, ), biomass production (C input to soil), plant growth stage and growing period, and soil cover, which in turn influence soil mineral $\mathrm{N}$, labile $\mathrm{C}$, WFPS, $\mathrm{O}_{2}$ demand and supply, and ultimately modified $\mathrm{N}_{2} \mathrm{O}$ emissions (Del Grosso et al., 2011).

\section{Conclusion}

In the present study, the DailyDayCent model was applied to simulate $\mathrm{N}_{2} \mathrm{O}$ emissions from two contrasting agro-ecosystems viz. mown-grassland and grain-cropland. Model performance was tested against high frequency data sets and a local sensitivity analysis was performed using 14 model parameters. Our modelling study shows 59\% greater annual $\mathrm{N}_{2} \mathrm{O}$ emission from the mown-grassland compared to the grain-cropping system, mainly due to higher $\mathrm{N}$-fertilization (120\%) in the former system. Our results demonstrated that DailyDayCent has the potential for successful simulation of overall daily $\mathrm{N}_{2} \mathrm{O}$ emissions from two contrasting agro-ecosystems in the study region, and the model would be a good tool, or at least a reasonable means for estimation of $\mathrm{N}_{2} \mathrm{O}$ inventory, projection of $\mathrm{N}_{2} \mathrm{O}$ emissions under different scenarios, and evaluation of different mitigation 
strategies against overall $\mathrm{N}_{2} \mathrm{O}$ emissions in the region. The model can simulate WFPS, soil temperature, SOC, soil $\mathrm{NH}_{4}{ }^{+}$and plant production accurately which is a prerequisite for the successful simulation of $\mathrm{N}_{2} \mathrm{O}$ emission. Our study indicated that higher variation in measurements of $\mathrm{N}_{2} \mathrm{O}$ flux could contribute to poor fit between model outputs and measurements. Further experimental and model improvement might be required to track $\mathrm{N}$ from decomposition of plant residue to plant uptake. Systematic discrepancies between measured and modelled $\mathrm{N}_{2} \mathrm{O}$ fluxes were obtained on a daily basis, but no definite pattern was obtained over the course of three year experiment. Significant differences between predicted and measured soil $\mathrm{NO}_{3}{ }^{-}$concentration was the most probable reason for such discrepancies. The current exercise suggests that the DailyDayCent sub-module responsible for $\mathrm{N}$ transformations might need to be improved for better simulation of soil mineral $\mathrm{N}$, particularly soil $\mathrm{NO}_{3}^{-}$, and $\mathrm{N}_{2} \mathrm{O}$ emission on a daily basis. There is still space for more model improvement for $\mathrm{N}_{2} \mathrm{O}$ flux on a daily basis, potentially by incorporating a range of other factors, which the model still does not account for, such as $\mathrm{N}_{2} \mathrm{O}$ uptake, spatial distribution of applied fertilizer-N, soil heterogeneity, depth distribution and composition of denitrifying microbes etc.

Sensitivity analysis showed that a total of four out of 14 parameters (FC, BD, SOC and $\mathrm{N}_{2}$ Oadjust_fc) were critical for simulation of $\mathrm{N}_{2} \mathrm{O}$ emissions, hence the need for careful estimation or site-specific calibration for successful modelling of $\mathrm{N}_{2} \mathrm{O}$ emission in the study region. Sensitivity analysis indicated that baseline SOC has a trade-off effect between plant production and $\mathrm{N}_{2} \mathrm{O}$ emissions. Our results also pointed out that an average error or uncertainty of $1{ }^{\circ} \mathrm{C}$ or $10 \%$ in the inputs of daily air temperature and precipitation, respectively, would not influence model performance for daily $\mathrm{N}_{2} \mathrm{O}$ emissions significantly. Sensitivity estimation also shows possible effects of future change in air temperature and precipitation on overall $\mathrm{N}_{2} \mathrm{O}$ emissions. Sensitivity analysis illustrated the opportunity of reducing $\mathrm{N}_{2} \mathrm{O}$ emissions by reducing the quantity of fertilizer- $\mathrm{N}$ in 
mown-grasslands without any reduction in hay production, though doing the same in the graincropping system could reduce the yield marginally.

Our present study is limited in application of one model only. Using other models together would be useful to test the quality of the input as well as model testing data, which are important for successful evaluation of model performance. A future multi-model approach on daily data would also be helpful for model improvement, by comparing different individual process/variables within the models against measurements. In our study, a local sensitivity analysis was performed; a full global sensitivity assessment and parameter estimation, including analysis of parameter correlation structure would be interesting and will be the subject of further study.

\section{Acknowledgement}

The lead author, Nimai Senapati (Post doc), was funded by the European community's Seventh Framework programme (FP2012-2015) under grant agreement no. 262060 (ExpeER). The research leading to these results has received funding principally from the ANR (ANR-11-INBS0001), AllEnvi, CNRS-INSU. We would like to thank the National Research Infrastructure 'Agroécosystèmes, Cycles Biogéochimique et Biodiversité (SOERE-ACBB http://www.soereacbb.com/fr/) for their support in field experiment. We are deeply indebted to Christophe de Berranger, Xavier Charrier for their substantial technical assistance and Patricia Laville for her valuables suggestion regarding $\mathrm{N}_{2} \mathrm{O}$ flux estimation.

\section{Compliance with ethical standards}

We declare that we do not have any conflict of interest. 
Abbasi, M.K., Adams, W.A., 2000. Gaseous N emission during simultaneous nitrificationdenitrification associated with mineral $\mathrm{N}$ fertilization to a grassland soil under field conditions. Soil Biol. Biochem. 32, 1251-1259.

Abdalla, M., Hastings, A., Helmy, M., Prescher, A., Osborne, B., Lanigan, G., et al., 2014. Assessing the combined use of reduced tillage and cover crops for mitigating greenhouse gas emissions from arable ecosystem. Geoderma 223-225, 9-20.

Abdalla, M., Jones, M., Yeluripati, J., Smith, P., Burke, J., Williams, M., 2010. Testing DayCent and DNDC model simulations of $\mathrm{N}_{2} \mathrm{O}$ fluxes and assessing the impacts of climate change on the gas flux and biomass production from a humid pasture. Atmos. Environ. 44, 2961-2970.

Abdalla, M., Wattenbach, M., Smith, P., Ambus, P., Jones, M., Williams, M., 2009. Application of the DNDC model to predict emissions of $\mathrm{N}_{2} \mathrm{O}$ from Irish agriculture. Geoderma 151: 327-337.

Angevin, F., 1999. Raisonnement de la fertilisation azotée. Le logiciel PCazote enPoitou-Charentes. Oléoscope 54, 32-34.

Arrouays, D., Deslais, W., Badeau, V., 2001. The carbon content of topsoil and its geographical distribution in France. Soil Use and Manage. 17, 7-11.

Arrouays, D., Pelissier, P., 1994. Changes in carbon storage in temperate humic loamy soils after forest clearing and continuous corn cropping in France. Plant Soil 160, 215-223.

Balesdent, J., Besnard, E., Arrouays, D., Chenu, C., 1998. The dynamics of carbon in particle-size fractions of soil in a forest-cultivation sequence. Plant Soil 201, 49-57.

Beek, C.L., Pleijter, M., Jacobs, C.M.J., Velthof, G.L., Groenigen, J.W., Kuikman, P.J., 2009. Emissions of $\mathrm{N}_{2} \mathrm{O}$ from fertilized and grazed grassland on organic soil in relation to groundwater level. Nutr. Cycl. Agroecosyst. 86, 331-340. 
Butterbach-Bahl, K., Baggs, E.M., Dannenmann, M., Kiese, R., Zechmeister-Boltenstern, S., 2013. Nitrous oxide emissions from soils: How well do we understand the processes and their controls? Phil. Trans. R. Soc. B Biol. Sci. 368.

Cardenas, L.M., Thorman, R., Ashlee, N., Butler, M., Chadwick, D., Chambers, B., et al., 2010. Quantifying annual $\mathrm{N}_{2} \mathrm{O}$ emission fluxes from grazed grassland under a range of inorganic fertiliser nitrogen inputs. Agric. Ecosyst. Environ. 136, 218-226.

Chabbi, A., Kögel-Knabner, I., Rumpel, C., 2009. Stabilised carbon in subsoil horizons is located in spatially distinct parts of the soil profile. Soil Biol. Biochem. 41, 256-261.

Chang, K.H., Warland, J., Voroney, P., Bartlett, P., Wagner-Riddle, C., 2013. Using DayCENT to simulate carbon dynamics in conventional and no-till agriculture. Soil Sci. Soc. Am. J. 77, 941950.

Chapuis-Lardy, L., Wrage, N., Metay, A., Chotte, J.L., Bernoux, M., 2007. Soils, a sink for $\mathrm{N}_{2} \mathrm{O}$ ? A review. Glob. Change Biol. 13, 1-17.

Congreves, K.A., Grant, B.B., Campbell, C.A., Smith, W.N., VandenBygaart, A.J., Kröbel, R., et al., 2015. Measuring and modeling the long-term impact of crop management on soil carbon sequestration in the semiarid Canadian prairies. Agron. J. 107, 1141-1154.

Cowan, N.J., Famulari, D., Levy, P.E., Anderson, M., Reay, D.S., Skiba, U.M., 2014. Investigating uptake of $\mathrm{N}_{2} \mathrm{O}$ in agricultural soils using a high-precision dynamic chamber method. Atmos. Meas. Tech. 7, 4455-4462.

Crutzen, P.J., Ehhalt, D.H., 1977. Effects of nitrogen fertilizers and combustion on the stratospheric ozone layer. Ambio 6, 112-117.

Čuhel, J., Šimek, M., Laughlin, R.J., Bru, D., Chèneby, D., Watson, C.J., et al., 2010. Insights into the effect of soil $\mathrm{pH}$ on $\mathrm{N}_{2} \mathrm{O}$ and $\mathrm{N}_{2}$ emissions and denitrifier community size and activity. Appl. Environ. Microbiol. 76, 1870-1878. 
Das, S., Adhya, T.K., 2014. Effect of combine application of organic manure and inorganic fertilizer on methane and nitrous oxide emissions from a tropical flooded soil planted to rice. Geoderma $213,185-192$.

Davidson, E.A., 2009. The contribution of manure and fertilizer nitrogen to atmospheric nitrous oxide since 1860. Nature Geosci. 2, 659-662.

Del Grosso, S.J., Halvorson, A.D., Parton, W.J., 2008a. Testing DAYCENT model simulations of corn yields and nitrous oxide emissions in irrigated tillage systems in Colorado. J. Environ. Qual. 37, 1383-1389.

Del Grosso, S.J., Mosier, A.R., Parton, W.J., Ojima, D.S., 2005. DAYCENT model analysis of past and contemporary soil $\mathrm{N}_{2} \mathrm{O}$ and net greenhouse gas flux for major crops in the USA. Soil Till. Res. 83, 9-24.

Del Grosso, S.J., Ogle, S.M., Parton, W.J., Breidt, F.J., 2010. Estimating uncertainty in $\mathrm{N}_{2} \mathrm{O}$ emissions from U.S. cropland soils. Glob. Biogeochem. Cycles 24, GB1009.

Del Grosso, S., Ojima, D., Parton, W., Mosier, A., Peterson, G., Schimel, D., 2002. Simulated effects of dryland cropping intensification on soil organic matter and greenhouse gas exchanges using the DAYCENT ecosystem model. Environ. Pollut. 116, S75-S83.

Del Grosso, S.J., Ojima, D.S., Parton, W.J., Stehfest, E., Heistemann, M., DeAngelo, B., et al., 2009. Global scale DAYCENT model analysis of greenhouse gas emissions and mitigation strategies for cropped soils. Glob. Planet. Change 67, 44-50.

Del Grosso, S.J., Parton, W.J., Keough, C.A., Reyes-Fox, M., 2011. Special features of the DayCent modeling package and additional procedures for parameterization, calibration, validation, and applications. In: Ahuja, L.R., Ma, L. (Eds.), Methods of Introducing System Models into Agricultural Research. American Society of Agronomy, Crop Science Society of America, Soil Science Society of America, Madison, WI 53711-5801, USA, pp. 155-176. 
Del Grosso, S.J., Parton, W.J., Mosier, A.R., Hartman, M.D., Brenner, J., Ojima, D.S., et al., 2001. Simulated interaction of carbon dynamics and nitrogen trace gas fluxes using the DAYCENT model. In: Shaffer, M.J., Ma, L., Hansen, S. (Eds.), Modeling Carbon and Nitrogen Dynamics for Soil Management. CRC Press, Boca Raton, Florida, pp. 303-332.

Del Grosso, S.J., Parton, W.J., Mosier, A.R., Ojima, D.S., Kulmala, A.E., Phongpan, S., 2000. General model for $\mathrm{N}_{2} \mathrm{O}$ and $\mathrm{N}_{2}$ gas emissions from soils due to dentrification. Glob. Biogeochem. Cycles 14, 1045-1060.

Del Grosso, S.J., Parton, W.J., Mosier, A.R., Walsh, M.K., Ojima, D.S., Thornton, P.E., 2006. DAYCENT national-scale simulations of nitrous oxide emissions from cropped soils in the United States. J. Environ. Qual. 35, 1451-1460.

Del Grosso, S.J., Parton, W.J., Ojima, D.S., Keough, C.A., Riley, T.H., Mosier, A.R., $2008 b$. DAYCENT simulated effects of land use and climate on county level $\mathrm{N}$ loss vectors in the USA. In: Hatfield, J.L., Follett, R.F. (Eds.), Nitrogen in the Environment: Sources, Problems, and Management. Publications from USDA-ARS/UNL Faculty, pp. 571-595.

Denman, K.L., Brasseur, G., Chidthaisong, A., Ciais, P., Cox, P.M., Dickinson, R.E., et al., 2007. Couplings between changes in the climate system and biogeochemistry. In: Solomon, S., Qin, D., Manning, M., Chen, Z., Marquis, M., Averyt, K.B., et al. (Eds.), Climate Change 2007: The Physical Science Basis. Contribution of Working Group I to the Fourth Assessment Report of the Intergovernmental Panel on Climate Change. Cambridge University Press, Cambridge, United Kingdom and New York, NY, USA, pp. 500-587.

Duru, M., 2004. Simplified nitrogen assessment of orchardgrass swards. Agron. J. 96, 1598-1605.

Eckard, R., Johnson, I., Chapman, D., 2006. Modelling nitrous oxide abatement strategies in intensive pasture systems. Int. Congr. Ser. 1293, 76-85. 
EPA, 2006. Inventory of U.S. Greenhouse Gas Emissions and Sinks: 1990-2004. United States Environmental Protection Agency, Washington, DC, USA.

EPA, 2010. Methane and Nitrous Oxide Emissions from Natural Sources. United States Environmental Protection Agency, Washington, DC, USA.

EPA, 2012. Global Anthropogenic Non- $\mathrm{CO}_{2}$ Greenhouse Gas Emissions: 1990-2030. Office of Atmospheric Programs Climate Change Division, U.S. Environmental Protection Agency, 1200 Pennsylvania Avenue, NW, Washington, DC 20460.

EPA, 2013. Inventory of U.S. Greenhouse Gas Emissions and Sink: 1990-2011. U.S. Environmental Protection Agency, Washington, DC, USA.

Farruggia, A., Gastal, F., Scholefield, D., 2004. Assessment of the nitrogen status of grassland. Grass Forage Sci. 59, 113-120.

Fitton, N., Datta, A., Hastings, A., Kuhnert, M., Topp, C.F.E., Cloy, J.M., et al., 2014a. The challenge of modelling nitrogen management at the field scale: simulation and sensitivity analysis of $\mathrm{N}_{2} \mathrm{O}$ fluxes across nine experimental sites using DailyDayCent. Environ. Res. Lett. 9, 095003 (pp.15).

Fitton, N., Datta, A., Smith, K., Williams, J.R., Hastings, A., Kuhnert, M., et al., 2014b. Assessing the sensitivity of modelled estimates of $\mathrm{N}_{2} \mathrm{O}$ emissions and yield to input uncertainty at a UK cropland experimental site using the DailyDayCent model. Nutr. Cycl. Agroecosyst. 99, 119133.

Flechard, C.R., Ambus, P., Skiba, U., Rees, R.M., Hensen, A., van Amstel, A., et al., 2007. Effects of climate and management intensity on nitrous oxide emissions in grassland systems across Europe. Agric. Ecosyst. Environ. 121, 135-152. 
Flechard, C.R., Neftel, A., Jocher, M., Ammann, C., Fuhrer, J., 2005. Bi-directional soil/atmosphere $\mathrm{N}_{2} \mathrm{O}$ exchange over two mown grassland systems with contrasting management practices. Glob. Change Biol. 11, 2114-2127.

Forster, P., Ramaswamy, V., Artaxo, P., Berntsen, J., Betts, R., Fahey, D.W., et al., 2007. Changes in atmospheric constituents and in radiative forcing. In: Solomon, S., Qin, D., Manning, M., Chen, Z., Marquis, M., Averyt, K., et al. (Eds.), Climate Change 2007 : The Physical Science Basis: Contribution of Working Group I to the Fourth Assessment Report of the Intergovernmental Panel on Climate Change. Cambridge University Press, Cambridge, United Kingdom and New York, NY, USA, pp. 130-234.

Gabrielle, B., Laville, P., Duval, O., Nicoullaud, B., Germon, J.C., Hénault, C., 2006. Process-based modeling of nitrous oxide emissions from wheat-cropped soils at the subregional scale. Glob. Biogeochem. Cycles 20, GB4018.

Groffman, P.M., Butterbach-Bahl, K., Fulweiler, R.W., Gold, A.J., Morse, J.L., Stander, E.K., et al., 2009. Challenges to incorporating spatially and temporally explicit phenomena (hotspots and hot moments) in denitrification models. Biogeochemistry 93, 49-77.

Guo, L.B., Gifford, R.M., 2002. Soil carbon stocks and land use change: a meta analysis. Glob. Change Biol. 8, 345-360.

IPCC, 2006. 2006 IPCC Guidelines for National Greenhouse Gas Inventories, Volume 4: Agriculture, Forestry and other Land Use. The Intergovernmental Panel on Climate Change, National Greenhouse Gas Inventories Programme [Eggleston, H.S., Buendia, L., Miwa, K., Ngara, T., Tanabe, K. (Eds.)], Kanagawa, Japan.

IPCC, 2007. Climate Change 2007: The Physical Science Basis. Contribution of Working Group I to the Fourth Assessment Report of the Intergovernmental Panel on Climate Change [Solomon, 
S., Qin, D., Manning, M., Chen, Z., Marquis, M., Averyt, K.B., et al. (Eds.)], Cambridge University Press Cambridge, United Kingdom and New York, USA.

Jarecki, M.K., Parkin, T.B., Chan, A.S.K., Hatfield, J.L., Jones, R., 2008. Comparison of DAYCENT-simulated and measured nitrous oxide emissions from a corn field. J. Environ. Qual. 37, 1685-1690.

Jeuffroy, M.H., Baranger, E., Carrouée, B., de Chezelles, E., Gosme, M., Hénault, C., et al., 2013. Nitrous oxide emissions from crop rotations including wheat, oilseed rape and dry peas. Biogeosciences 10, 1787-1797.

Kamphake, L.J., Hannah, S.A., Cohen, J.M., 1967. Automated analysis for nitrate by hydrazine reduction. Water Res. 1, 205-216.

Kaplan, J.O., Krumhardt, K.M., Zimmermann, N., 2009. The prehistoric and preindustrial deforestation of Europe. Quat. Sci. Rev. 28, 3016-3034.

Kim, D.G., Rafique, R., Leahy, P., Cochrane, M., Kiely, G., 2014. Estimating the impact of changing fertilizer application rate, land use, and climate on nitrous oxide emissions in Irish grasslands. Plant Soil 374, 55-71.

Kunrath, T.R., de Berranger, C., Charrier, X., Gastal, F., de Faccio Carvalho, P.C., Lemaire, G., et al., 2015. How much do sod-based rotations reduce nitrate leaching in a cereal cropping system? Agric. Water Manage. 150, 46-56.

Laville, P., Lehuger, S., Loubet, B., Chaumartin, F., Cellier, P., 2011. Effect of management, climate and soil conditions on $\mathrm{N}_{2} \mathrm{O}$ and $\mathrm{NO}$ emissions from an arable crop rotation using high temporal resolution measurements. Agric. For. Meteorol. 151, 228-240.

Lee, J., Pedroso, G., Linquist, B.A., Putnam, D., van Kessel, C., Six J., 2012. Simulating switchgrass biomass production across ecoregions using the DAYCENT model. GCB Bioenergy 4, 521533. 
Lemaire, G., Jeuffroy, M.H., Gastal F., 2008. Diagnosis tool for plant and crop N status in vegetative stage: Theory and practices for crop N management. Eur. J.Agron. 28, 614-624.

Linn, D.M., Doran, J.W., 1984. Effect of water-filled pore space on carbon dioxide and nitrous oxide production in tilled and nontilled soils. Soil Sci. Soc. Am. J. 48, 1267-1272.

Liu, C., Wang, K., Meng, S., Zheng, X., Zhou, Z., Han, S., et al., 2011. Effects of irrigation, fertilization and crop straw management on nitrous oxide and nitric oxide emissions from a wheat-maize rotation field in northern China. Agric. Ecosyst. Environ. 140, 226-233.

Liu, X.J., Mosier, A.R., Halvorson, A.D., Zhang, F.S., 2006. The impact of nitrogen placement and tillage on $\mathrm{NO}, \mathrm{N}_{2} \mathrm{O}, \mathrm{CH}_{4}$ and $\mathrm{CO}_{2}$ fluxes from a clay loam soil. Plant Soil 280, 177-188.

Martin, M.P., Wattenbach, M., Smith, P., Meersmans, J., Jolivet, C., Boulonne, L., et al., 2011. Spatial distribution of soil organic carbon stocks in France. Biogeosciences 8, 1053-1065.

Mather, A.S., Fairbairn, J., Needle, C.L., 1999. The course and drivers of the forest transition: The case of France. J. Rural Stud. 15, 65-90.

Mathieu, O., Lévêque, J., Hénault, C., Milloux, M.J., Bizouard, F., Andreux, F., 2006. Emissions and spatial variability of $\mathrm{N}_{2} \mathrm{O}, \mathrm{N}_{2}$ and nitrous oxide mole fraction at the field scale, revealed with $15 \mathrm{~N}$ isotopic techniques. Soil Biol. Biochem. 38, 941-951.

Meersmans, J., Martin, M., Lacarce, E., De Baets, S., Jolivet, C., Boulonne, L., et al., 2012. A high resolution map of French soil organic carbon. Agron. Sustain. Dev. 32, 841-851.

Moni, C., Chabbi, A., Nunan, N., Rumpel, C., Chenu, C., 2010. Spatial dependance of organic carbon-metal relationships. A multi-scale statistical analysis, from horizon to field. Geoderma $158,120-127$.

Mosier, A., Kroeze, C., 2000. Potential impact on the global atmospheric $\mathrm{N}_{2} \mathrm{O}$ budget of the increased nitrogen input required to meet future global food demands. Chemosphere Glob. Change Sci. 2, 465-473. 
Necpálová, M., Anex, R.P., Fienen, M.N., Del Grosso, S.J., Castellano, M.J., Sawyer, J.E., et al., 2015. Understanding the DayCent model: Calibration, sensitivity, and identifiability through inverse modeling. Environ. Model. Softw. 66, 110-130.

Omonode, R.A., Smith, D.R., Gál A, Vyn, T.J., 2011. Soil nitrous oxide emissions in corn following three decades of tillage and rotation treatments. Soil Sci. Soc. Am. J. 75, 152-163.

Parton, W.J., Hartman, M., Ojima, D., Schimel, D., 1998. DAYCENT and its land surface submodel: Description and testing. Glob. Planet. Change 19, 35-48.

Parton, W.J., Holland, E.A., Del Grosso, S.J., Hartman, M.D., Martin, R.E., Mosier, A.R., et al., 2001. Generalized model for $\mathrm{NO}_{\mathrm{x}}$ and $\mathrm{N}_{2} \mathrm{O}$ emissions from soils. J. Geophys. Res. 106, 1740317419.

Paul, E.A., 2006. Soil Microbiology and Biochemistry: 3rd ed. Academic Press.

Poeplau, C., Don, A., Vesterdal, L., Leifeld, J., Van Wesemael, B.A.S., Schumacher, J., et al., 2011. Temporal dynamics of soil organic carbon after land-use change in the temperate zone carbon response functions as a model approach. Glob. Change Biol. 17, 2415-2427.

Rafique, R., Fienen, M., Parkin, T., Anex, R., 2013. Nitrous oxide emissions from cropland: a procedure for calibrating the DayCent biogeochemical model using inverse modelling. Water Air Soil Pollut. 224, 1-15.

Rafique, R., Hennessy, D., Kiely, G., 2011. Nitrous oxide emission from grazed grassland under different management systems. Ecosystems 14, 563-582.

Rafique, R., Kumar, S., Luo, Y., Xu, X., Li, D., Zhang, W., et al., 2014. Estimation of greenhouse gases $\left(\mathrm{N}_{2} \mathrm{O}, \mathrm{CH}_{4}\right.$ and $\left.\mathrm{CO}_{2}\right)$ from no-till cropland under increased temperature and altered precipitation regime: A DAYCENT model approach. Glob. Planet. Change 118, 106-114.

Ravishankara, A.R., Daniel, J.S., Portmann, R.W., 2009. Nitrous oxide $\left(\mathrm{N}_{2} \mathrm{O}\right)$ : The dominant ozonedepleting substance emitted in the 21st century. Science $326,123-125$. 
Saxton, K.E., Rawls, W.J., 2006. Soil water characteristic estimates by texture and organic matter for hydrologic solutions. Soil Sci. Soc. Am. J. 70, 1569-1578.

Scheer, C., Del Grosso, S.J., Parton, W.J., Rowlings, D.W., Grace, P.R., 2014. Modeling nitrous oxide emissions from irrigated agriculture: Testing DayCent with high-frequency measurements. Ecol. Appl. 24, 528-538.

Senapati, N., Chabbi, A., Gastal, F., Smith, P., Mascher, N., Loubet, B., et al., 2014. Net carbon storage measured in a mowed and grazed temperate sown grassland shows potential for carbon sequestration under grazed system. Carbon Manage. 5, 131-144.

Shan, J., Yan, X., 2013. Effects of crop residue returning on nitrous oxide emissions in agricultural soils. Atmos. Environ. 71, 170-175.

Signor, D., Cerri, C.E.P., 2013. Nitrous oxide emissions in agricultural soils: a review. Pesq. Agropec. Trop. 43, 322-338.

Smith, J., Smith , P., 2007. Environmental Modelling: An Introduction. Oxford University Press, New York, USA.

Smith, J.U., Smith, P., Addiscott, T.M. , 1996. Quantitative methods to evaluate and compare soil organic matter (SOM) models. In: Powlson, D.S., Smith, P., Smith, J.U. (Eds.), Evaluation of Soil Organic Matter Models Using Existing Long-Term Datasets. NATO ASI Series I: Global Environmental Change, Vol. 38. Springer-Verlag, Berlin Heidelberg, pp. 181-199.

Smith, P., Albanito, F., Bell, M., Bellarby, J., Blagodatskiy, S., Datta, A., et al., 2012. Systems approaches in global change and biogeochemistry research. Phil. Trans. R. Soc. B 367, 311 321.

Smith, P., Smith, J.U., Powlson, D.S., McGill, W.B., Arah, J.R.M., Chertov, O.G., et al., 1997. A comparison of the performance of nine soil organic matter models using datasets from seven long-term experiments. Geoderma 81, 153-225. 
Stehfest, E., Heistermann, M., Priess, J.A., Ojima, D.S., Alcamo, J., 2007. Simulation of global crop production with the ecosystem model DayCent. Ecol. Model. 209, 203-219.

Stehfest, E., Müller, C., 2004. Simulation of $\mathrm{N}_{2} \mathrm{O}$ emissions from a urine-affected pasture in New Zealand with the ecosystem model DayCent. J. Geophys. Res. 109, D03109.

Syakila, A., Kroeze, C., 2011. The global nitrous oxide budget revisited. Greenhouse Gas Measure. Manage. 1, 17-26.

Trost, B., Prochnow, A., Drastig, K., Meyer-Aurich, A., Ellmer, F., Baumecker, M., 2013. Irrigation, soil organic carbon and $\mathrm{N}_{2} \mathrm{O}$ emissions. A review. Agron. Sustain. Dev. 33, 733-749.

Venterea, R.T., Burger, M., Spokas, K.A., 2005. Nitrogen oxide and methane emissions under varying tillage and fertilizer management. J. Environ. Qual. 34, 1467-1477.

WMO, 2010. Greenhouse Gas Bulletin No. 6: The state of greenhouse gases in the atmosphere based on observations through 2009. World Meteorological Organization, Geneva. http://www.wmo.int/pages/prog/arep/gaw/ghg/GHGbulletin.html

WMO, 2014. Greenhouse Gas Bulletin: The State of Greenhouse Gases in the Atmosphere Based on Global Observations through 2013. World meteorological Organization, Geneva. http://www.wmo.int/pages/prog/arep/gaw/ghg/GHGbulletin.html

Wrage, N., Lauf, J., del Prado, A., Pinto, M., Pietrzak ,S., Yamulki, S., et al., 2004. Distinguishing sources of $\mathrm{N}_{2} \mathrm{O}$ in European grasslands by stable isotope analysis. Rapid Commun. Mass Spectrom. 18, 1201-1207.

Wrage, N., Velthof, G.L., van Beusichem, M.L., Oenema, O., 2001. Role of nitrifier denitrification in the production of nitrous oxide. Soil Biol. Biochem. 33, 1723-1732.

Xuan, Z, Li-yong, X., Li-ping, G., Jing-wei, F., 2016. Modelling the changes of soil organic carbon under different management practices using Daycent model in North China. Chin. J. Appl. Ecol. 27, 539-548. 

$9 \quad$ February 2014.

\section{Figure caption}

Yu, K., Chen G, Struwe, S., Kjøller, A., 2000. Production and reduction of nitrous oxide in agricultural and forest soils. J. Appl. Ecol. 11, 385-389.

Zhang, Y., Qian, Y., Bremer, D.J., Kaye, J.P., 2013. Simulation of nitrous oxide emissions and estimation of global warming potential in turfgrass systems using the daycent model. J. Environ. Qual. 42, 1100-1108.

Fig. 1. SOERE-ACBB long-term experiment, Lusignan, France.

Fig. 2. Daily air temperature and precipitation during the experimental period March 2011 to

Fig. 3. Simulated soil organic carbon (SOC) under native vegetation (equilibrium-run,) past land use changes and present conditions in the top $20 \mathrm{~cm}$ soil layer in mown-grassland and grain-cropland (upper), and current measured and simulated SOC in the top $20 \mathrm{~cm}$ soil layer in mown-grassland and grain-cropland (lower).

Fig. 4. Simulated water filled pore space (WFPS) at $10 \mathrm{~cm}$ soil depth in mown-grassland and graincropland during 2011-2014 (top), and measured and simulated WFPS at $10 \mathrm{~cm}$ soil depth in mowngrassland during 2011-2013.

Fig. 5. Simulated soil temperature at $10 \mathrm{~cm}$ soil depth in mown-grassland and grain-cropland during 2011-2014 (top), and measured and simulated soil temperature at $10 \mathrm{~cm}$ soil depth in mowngrassland during 2011-2013.

Fig. 6. Simulated above-ground live biomass, total nitrogen uptake and nitrogen leaching in mowngrassland and grain-cropland during the experimental period March 2011 to February 2014. C: mowing event, T: tillage, $\mathrm{S}$ : sowing, $\mathrm{H}$ : harvesting, 36-90: amount of fertilizer nitrogen $\left(\mathrm{kg} \mathrm{N} \mathrm{ha}^{-1}\right)$. 
1 Fig. 7. Measured and simulated cumulative hay production in mown-grassland (upper), and

2 measured and simulated total above ground biomass, grain and straw yield of corn, wheat and barley

3 in cropland during the experimental period March 2011 to February 2014.

4 Fig. 8. Measured and simulated ammonium $\left(\mathrm{NH}_{4}{ }^{+}\right)$and nitrate $\left(\mathrm{NO}_{3}{ }^{-}\right)$concentrations in mown5 grassland (top two) and grain-cropland (bottom two) during the experimental period March 2011 to

6 February 2014. C: mowing event, T: tillage, S: sowing, H: harvesting, 36-90: amount of fertilizer 7 nitrogen $\left(\mathrm{kg} \mathrm{N} \mathrm{ha}^{-1}\right)$.

8 Fig. 9. Simulated cumulative $\mathrm{N}_{2} \mathrm{O}$ flux in mown-grassland and grain-cropland (top), measured and 9 simulated $\mathrm{N}_{2} \mathrm{O}$ flux in mown-grassland with all measured values (second top) and excluding six 10 larger measured fluxes for elucidating $\mathrm{N}_{2} \mathrm{O}$ flux on finer scale (second bottom), and measured and 11 simulated $\mathrm{N}_{2} \mathrm{O}$ flux in grain-cropland (bottom) during the experimental period March 2011 to 12 February 2014. C: mowing event, T: tillage, S: sowing, H: harvesting, 36-90: amount of fertilizer 13 nitrogen $\left(\mathrm{kg} \mathrm{N} \mathrm{ha}^{-1}\right)$. 